\title{
Aeroelastic Response of Bird-Damaged Fan Blades Using a Coupled CFD/CSD Framework
}

\author{
Eric R. Muir* and Peretz P. Friedmann ${ }^{\dagger}$ \\ Department of Aerospace Engineering, The University of Michigan, Ann Arbor, MI, 48109, USA
}

\begin{abstract}
The aeroelastic response of a bird-damaged fan stage at the inlet of a high-bypass ratio turbofan engine is examined using a combined CFD/CSD model. ANSYS CFX is used for the computational fluid dynamic (CFD) calculations combined with the ANSYS Multifield (MFX) solver that couples ANSYS CFX with ANSYS Mechanical APDL to perform aeroelastic response calculations. The damaged fan sector consists of 5 blades that represent the geometry resulting from a numerical bird strike simulation. The forced response of the undamaged blades downstream of the damaged sector exhibits the highest level of structural response. The structural response of these undamaged blades is dominated by the first bending mode and increases in amplitude with time. The aeroelastic response shows a similar behavior, with the downstream undamaged blades exhibiting a growing structural response that is dominated by the first bending mode. The aeroelastic response of the damaged blades also contains contributions from the second torsion mode. An examination of the work exerted by the aerodynamic forces suggests that the growth in blade response for the upstream damaged blade is due to an aeroelastic behavior that may be indicative of a potential instability.
\end{abstract}

\section{Nomenclature}

$\begin{array}{ll}D & \text { Number of RBF driver points } \\ \dot{m} & \text { Mass flow rate } \\ \dot{m}_{R} & \text { Referred mass flow rate } \\ q_{m} & \text { Generalized degree of freedom of the } m^{\text {th }} \text { mode } \\ p & \text { Aerodynamic static pressure } \\ P & \text { Aerodynamic total pressure } \\ P R & \text { Total pressure ratio } \\ R & \text { Blade tip radius } \\ S & \text { CFD element surface area } \\ t & \text { Time } \\ T & \text { Aerodynamic total temperature } \\ U_{\theta} & \text { Angular deformation (cylindrical coordinates) } \\ W_{A R} & \text { Aerodynamic work calculated from aeroelastic calculations } \\ W_{F R} & \text { Aerodynamic work calculated from forced response calculations } \\ \mathbf{a}_{\boldsymbol{\Omega}} & \text { Assembled centrifugal acceleration vector } \\ \mathbf{C} & \text { RBF interpolant coefficient vector } \\ \mathbf{F}_{\text {aero }} & \text { Assembled aerodynamic force vector } \\ \mathbf{F}_{\boldsymbol{\Omega}} & \text { Assembled centrifugal force vector } \\ \mathbf{K} & \text { Assembled FEM stiffness matrix }\end{array}$

*Ph. D. Candidate, Student Member AIAA.

${ }^{\dagger}$ Francois-Xavier Bagnound Professor of Aerospace Engineering, Fellow AIAA and AHS. 


(1)

Assembled FEM mass matrix

M

n

$\mathbf{Q}^{j}$

$\mathbf{r}$

U

$\mathbf{x}=(x, y, z)$

$\mathbf{x}^{d}=\{x, y, z\}^{T}$

$\mathbf{x}^{e}=\{x, y, z\}^{T}$

Coordinate Systems

$<r, \theta, z>$

$<x, y, z>$

\section{Greek Symbols}

$\alpha$

$\beta$

$\gamma$

$\varepsilon$

$\tau$

$\phi$

$\Gamma$

$\Lambda$

$\Lambda_{\text {ref }}$

$\Omega$

$\delta$

$\varsigma$

$\hat{\boldsymbol{\varsigma}}$

$\varphi$

$\boldsymbol{\Phi}_{m}$

$\boldsymbol{\Omega}=\{0,0, \Omega\}^{T}$

Subscripts

$m$

$S T D$

Superscript

j

$(\dot{)})=\mathrm{d} / \mathrm{dt}$

\section{Abbreviations}

1B

$2 \mathrm{~B}$

$1 \mathrm{~T}$

$3 \mathrm{~B}$

$2 \mathrm{~T}$

CAD

CFD

CSD
Element normal vector

Aerodynamic force vector on $j$-th node of CFD mesh

Radius vector

Assembled nodal deformation vector

Nodal position vector

$\mathrm{RBF}$ driver point

RBF evaluation point

Global cylindrical coordinate system

Global Cartesian coordinate system

HHT- $\alpha$ time-integration parameter

HHT- $\alpha$ time-integration parameter

HHT- $\alpha$ time-integration parameter

FSI load transfer convergence tolerance

Aerodynamic viscous wall shear stress

Radial basis function

CFD mesh diffusivity

CFD element volume

Reference CFD element volume

Engine rotation speed

CFD mesh displacement

CFD mesh deformation vector

$\mathrm{RBF}$ interpolant of the CFD mesh deformation

FSI interface load/displacement vector

Mode shape deformation of the $m^{\text {th }}$ mode

Engine rotation vector

Mode number

Standard atmosphere conditions

Reference to node $j$ in the CFD mesh

Differentiation with time

First bending mode

Second bending mode

First torsion mode

Third bending mode

Second torsion mode

Computer Aided Design

Computational Fluid Dynamics

Computational Structural Dynamics 


$\begin{array}{ll}\text { FEM } & \text { Finite Element Method } \\ \text { FSI } & \text { Fluid Structure Interface } \\ \text { RANS } & \text { Reynolds-averaged Navier-Stokes } \\ \text { RBF } & \text { Radial basis function } \\ \text { RBFN } & \text { Radial basis function network }\end{array}$

\section{Introduction, Background, and Objectives}

$\mathrm{B}^{\mathrm{IRD}}$ strike on jet engine fan blades is important for the design of both civilian and military aircraft. Bird strikes occur primarily during takeoff and landing due to the tendency of birds to congregate in the vicinity of the ground! $!^{1}$ The low altitude at which bird strikes occur limits recovery options and enhances the risk due to bird strike. The turbofan engines used in commercial and military aircraft have a large intake area covered by fan blades that increases the chance of bird strikes. Furthermore, the thin, low aspect ratio, low camber fan blades used in modern turbofans are structurally and aerodynamically optimized for efficiency at normal operating conditions, and bird damage induces off-design operation!2 Therefore, turbofan designs represent a sophisticated trade-off between structural integrity, propulsive efficiency, and robustness under bird strike.

During bird-strike, the bird hits the fan blades, fragments, and propagates through the engine core and bypass duct. The impact can cause substantial deformation of the blade leading edge combined with bending and twist of the blade.$^{\frac{3}{3}}$ It can also induce crack propagation and fatigue failure.$^{3}$ Furthermore, the structural dynamics and unsteady aerodynamic loading caused by bird damage induce a complex aeroelastic response problem that can lead to aeroelastic instability $4 \sqrt[45]{5}$ Predicting the aeroelastic behavior of a bird damaged fan blade represents a significant design barrier in the development of improved-efficiency turbofan engines.

The Federal Aviation Administration (FAA) mandates comprehensive standards for bird strike resistance. ${ }^{6}$ These standards require that each engine maintain $75 \%$ of the maximum rated thrust and meet engine handling requirements for a series of post bird strike operating conditions that simulate an emergency landing sequence. Successful demonstration of compliance with Federal Aviation Regulations (FAR) Part 33 in which a bird is fired with an air cannon at a test stand mounted, running engine is required for certification. Several complete-engine tests are required to demonstrate compliance with these regulations, and each test destroys a new engine. Therefore, the cost associated with engine certification for bird-strike is high.

Complete-engine tests are infeasible within the design iteration process due to the associated cost. As a result, approximate component-based engine tests are performed to isolate the bird damage by firing a bird at a subset of the engine (typically the fan stage) that is rotated in a vacuum 1$] 3[7$ Such tests determine the ability of the fan blades to retain their structural integrity during and after a bird strike event. The damaged fan stage is then installed in an otherwise undamaged engine to assess the effect of the bird-damaged fan blades on the engine aerodynamic performance and aeroelastic response. Experimental tests demonstrate that bird damage may reduce flutter margins and produce rotating stall, reinforcing the importance of an accurate bird-strike aeroelastic analysis $\underline{\underline{8}}$

Numerical simulations provide a cost effective means for assessing the aerodynamic loading and aeroelastic behavior of a damaged fan. However, the combined aerodynamic and structural dynamic modeling of a bird-damaged fan assembly, where the damage is typically isolated to a sector of blades, is a complex problem. The structural model must accommodate the asymmetry caused by the bird-damaged fan blades and the aerodynamic model must be time-accurate, nonlinear, viscous, and include a turbulence model to address time-dependent flow separation and reattachment. ${ }^{9}$ Computational structural dynamics (CSD) based on the finite element method (FEM) are typically used to model the bird impact and resulting structural response since it can represent complex material behavior and non-linear geometric deformations 10 -16 Computational fluid dynamics (CFD) is required to accurately capture the complex flow phenomena associated with bird damaged turbofans $\mathbb{1 7}[18$ Reliable CSD and CFD methods exist to compute the bird impact, structural dynamic response, and unsteady aerodynamic loads of a damaged fan blade. However, due to the computational times required for CFD methods, the structural and aerodynamic computations are typically performed separately in an uncoupled or loosely coupled manner. Therefore, the aeroelastic effects may be inaccurate.

Despite its importance, only a limited number of computational studies have considered the aeroelastic response of a bird-damaged fan. In a unique set of studies, Imregun et al 8$] 9$ examined the aeroelastic stability of a bird-damaged fan using a fully coupled CFD/CSD formulation in the time domain in which 
the form of the bird-damage is "assumed" and isolated to two blades. In Ref. 9, the fully coupled analysis demonstrates instability of the first torsion mode of a damaged blade; however, it is unclear if the growth in modal displacement is the result of a flutter mechanism or the strong wake shed by the upstream damaged blade. In Ref. 8 , the aeroelastic response was also found to be sensitive to flight conditions, with flutter margins reduced at low pressure ratios and rotating stall occurring at high pressure ratios. Rotating stall is a well-known unsteady flow phenomena in axial compressors in which an upstream flow disturbance causes a sector of the fan blades to stall, typically at the blade tip. The stalled blades result in pockets of stagnant air, denoted stall cells, that rotate circumferentially at the blade tips producing large, unsteady aerodynamic loads on the blades.

These studies provide insight into the aerodynamic behavior and aeroelastic response of a bird-damaged fan. However, the damage considered in Refs. 8 and 9 was not representative of realistic blade damage due to bird-strike certification tests, where leading edge damage over a large region of the blade span is accompanied by global bending and twist of the blade. Also, the turbofan geometries in these studies did not resemble modern, high-bypass turbofans and the damaged sector is limited to two blades. Furthermore, the aeroelastic response calculations of Refs. 8 and 9 were performed at $70 \%$ engine rotational speed, while bird-strike typically occurs during take-off at $100 \%$ engine rotation speed.

For improved understanding of the bird-strike problem, a computational aeroelastic study of a bird damaged commercial turbofan operating at take-off conditions is needed, where the bird damage is representative of experimental bird strike tests or accurate numerical simulation of the bird-strike event. In Ref. 19, the authors presented an aerodynamic model suitable for use in an aeroelastic study of a bird-damaged commercial turbofan engine together with the steady-state and unsteady flow field resulting from the bird-damaged fan. Subsequently in Ref. 20, the aerodynamic model and a structural dynamic model were combined and forced response calculations were performed to gain insight into this complex system behavior. The current study extends the forced response framework to accommodate two-way coupling between the aerodynamic and structural dynamic models of the bird damaged fan and aeroelastic response calculations are performed. The overall objective of this paper is to compare the blade response resulting from one-way forced response and fully-coupled aeroelastic response calculations and thus assess the role of complete aeroelastic coupling on the response. The specific objectives of this study are:

1. Describe a coupled CFD/CSD framework that is suitable for a fully-coupled aeroelastic stability and response calculation of bird damaged turbofans.

2. Describe the steady and unsteady flow associated with a fan sector consisting of five bird-damaged blades that are representative of a practical bird-strike configuration.

3. Study in detail the forced response and aeroelastic response of a bird-damaged fan stage under post bird-strike conditions.

4. Compare the aerodynamic work calculated from the forced response and aeroelastic response calculations to identify the potential for aeroelastic instability.

\section{Fan Blade Geometry}

The turbofan geometry examined is representative of a commercial, high-bypass ratio turbofan. The aerodynamic geometry of each fan blade is described by a set of constant-span cross-sections referred to as blade profiles, as shown in Fig. 1(a). The structural geometry is described by a computer aided design (CAD) model of the fan blade, as shown in Fig. 1(b), defined by the aerodynamic blade profiles.

LS-DYNA is employed to numerically simulate the bird strike problem and obtain the bird-damaged configuration. The LS-DYNA code is a general purpose FEM program that has been used extensively to model bird-strike problems, and it has proven itself to be a reliable tool for modeling blade damage $\frac{10}{10}$ The simulated bird-strike event mimics a typical bird-strike experimental test sequence in vacuum: spin the fan stage at a specified engine rotational speed, fire a bird at the fan stage, continue to spin the engine until the transient response of the blades subsides, slow the fan stage to zero engine rotational speed. In this process, the rotating fan stage is referred to as "hot" and differs from the non-rotating "cold" fan stage due to centrifugal effects. Furthermore, the fan stage before the bird-strike is referred to as "undamaged" where as the fan stage after the bird-strike is referred to as "damaged". 


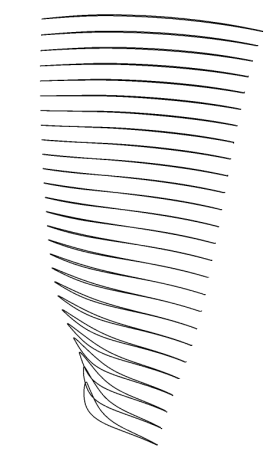

(a) Aerodynamic blade profiles.

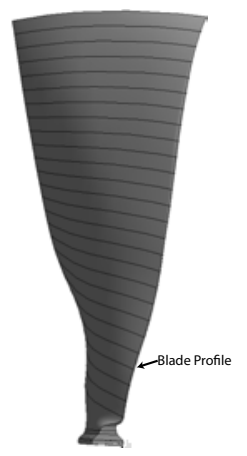

(b) Undamaged blade.

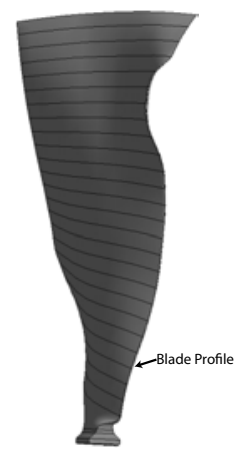

(c) Damaged blade.

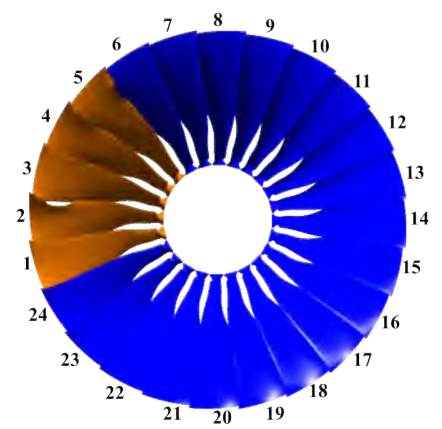

(d) Bird-damaged fan.

Figure 1: Aerodynamic blade profiles and the CAD model of the damaged fan.

The damaged geometry considered is due to a single 2.5 pound (lb) bird ingested at take-off conditions at a strike location of $70 \%$ blade span. The bird strike involves a subset of 5 blades, and the remaining blades are undamaged. The blade damage is interpolated to generate the damaged blade profiles that define the aerodynamic and CAD-based structural geometries of the bird-damaged fan blades. Figure 1(c) depicts the CAD model of a damaged blade defined by the aerodynamic blade profiles. Figure 1(d) shows the CAD model of the full, damaged fan, where the damaged blades are highlighted in orange and the blades are numbered.

\section{Aerodynamic Model}

The ANSYS CFX commercial aerodynamic solver is used to model the compressible unsteady flow governed by the Reynolds-averaged Navier Stokes (RANS) equations. ANSYS CFX utilizes a finite volume approach that yields a near second-order accurate spatial discretization. A second-order accurate backward Euler time-integration scheme is used for the unsteady calculations. The k- $\epsilon$ turbulence model is employed and scalable wall functions are used to resolve the near-wall boundary layer. The fluid is assumed to be ideal and calorically perfect.

\section{A. Computational Domain}

The CFD calculation is restricted to an isolated fan stage suitable for prediction of the performance characteristics and unsteady aerodynamic behavior of a bird-damaged fan. The fan stage starts downstream of the engine inlet, extends into the bypass duct and core duct, and includes a set of fan blades, a rotating hub, a stationary shroud, and a stationary splitter, illustrated by Fig. 2. The hub, shroud, and splitter geometries are defined by two-dimensional curves in the $r-z$ plane, and the three-dimension hub, shroud, and splitter surfaces are obtained by full revolution of these curves about the engine centerline. The surfaces connecting the edges of the hub, shroud, and splitter define the inflow, bypass duct outflow, and core duct outflow boundaries of the computational domain. A clearance between the blade tip and shroud is specified to accurately account for the influence of the tip gap on flow losses and shock structure.

\section{B. Computational Mesh}

ANSYS TurboGrid is utilized to generate a high-quality, structured CFD mesh of hexahedral elements for an undamaged single blade passage. ANSYS TurboGrid cannot accommodate geometries with a splitter that bisects the domain outflow. Instead, ANSYS Meshing is used to create an unstructured hexahedral mesh for the outlet. Conventional mesh topologies, such as H-Grid, J-Grid, C-Grid, L-grid, and O-grid, require a substantial amount of user manipulation to construct a CFD mesh of acceptable quality, particularly for complex blade geometries. Furthermore, these conventional topologies often result in an overly fine mesh within the blade passage to ensure a sufficient boundary layer resolution. ANSYS TurboGrid contains an 


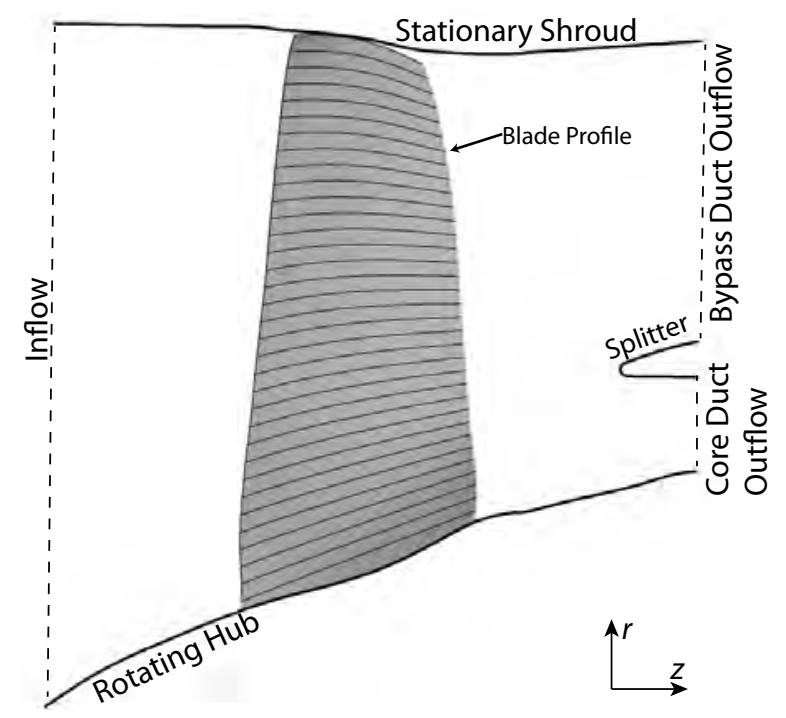

Figure 2: Meridional cross-section of the fan stage computational domain.

Automatic Topology and Meshing (ATM) optimized topology method that is used to create high-quality, structured meshes of an undamaged fan without the constraints of conventional topologies.

The mesh topology, mesh density, and boundary layer resolution for the undamaged CFD mesh are determined by the physical flow phenomena anticipated and the degree of accuracy desired from the CFD solution. Proper resolution of the boundary layer and tip gap is essential to capture the shock structure and flow losses due to viscosity in the boundary layer and flow leakage through the tip gap. Mesh sensitivity studies were conducted in Ref. 19, and it was concluded that the "coarse" mesh identified in Ref. 19 is sufficiently accurate for the objectives of the current study. A constant-span cross-section at $75 \%$ blade span is shown in Fig. 3(a), and an overall meridional view of the computational mesh of the coarse mesh for a single blade passage is depict in Fig. 3(b). The mesh consists of 10.4 million nodes and 9.7 million elements.

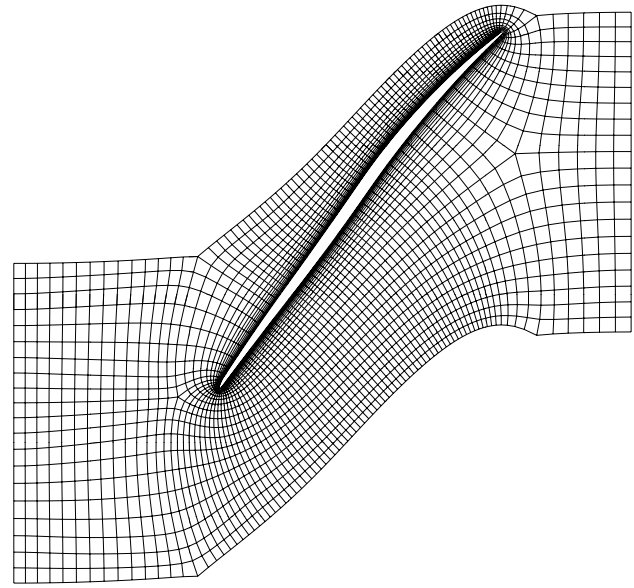

(a) CFD mesh at $75 \%$ blade span.

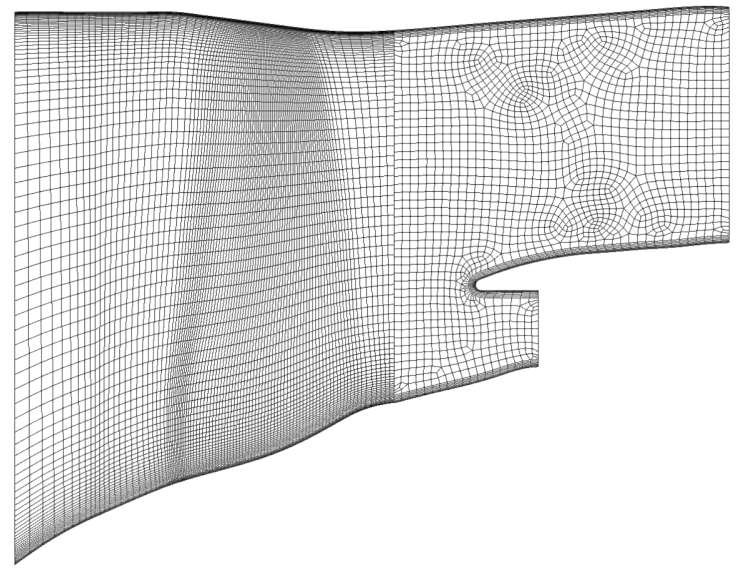

(b) Meridional view of CFD mesh.

Figure 3: Constant-span and meridional cross-sections of the CFD mesh.

The ANSYS TurboGrid ATM topology is not applicable for full wheel geometries that include a set of damaged blades. To extend the high mesh quality produced by the ANSYS Turbo Grid ATM mesh topology to the damaged fan geometry, the automated mesh deformation scheme presented in Ref. 19 is utilized. This procedure employs a radial basis function network (RBFN) to interpolate the deformation from the bird damaged blades to the CFD mesh of the undamaged wheel. RBFN interpolation is an effective tool 
for multivariate interpolation and has been successfully utilized for large-amplitude mesh deformation in aeroelastic applications and CFD-based aerodynamic shape optimization studies.21 26

A RBFN consists of a linear combination of radial basis functions (RBF) used to map the deformation prescribed at the fluid domain boundaries to the interior CFD mesh. A RBF, $\phi$, is a scalar function whose value depends only on the distance from the evaluation point, $\mathbf{x}^{e}$, to the origin, such that $\phi=\phi\left(\left\|\mathbf{x}^{e}\right\|\right)$. Provided a set of $D$ driver points at which the deformation is known, the RBF interpolant of the deformation field is constructed in the form given by Eq. (1). The RBF fitting coefficients, $\mathbf{C}$ are uniquely determined by ensuring the deformation evaluated with the RBF interpolant at the driver points is equal to the prescribed deformation, as given in Eq. 22). The choice of RBF is important to ensure the best possible representation of the deformation field and resulting mesh quality. Reference 26 demonstrated that the volume spline defined by $\phi\left(\left\|\mathbf{x}^{e}\right\|\right)=\left\|\mathbf{x}^{e}\right\|$ is an ideal RBF for CFD mesh deformation; therefore, the volume spline is used in this study where the norm is evaluated as the Euclidean distance: $\left\|\mathbf{x}^{e}\right\|=\sqrt{x^{2}+y^{2}+z^{2}}$.

$$
\begin{gathered}
\hat{\boldsymbol{\varsigma}}\left(\mathbf{x}^{e}\right)=\sum_{p=1}^{D} \mathbf{C}_{p} \phi\left(\left\|\mathbf{x}^{e}-\mathbf{x}_{p}^{d}\right\|\right) \\
\boldsymbol{\varsigma}_{s}=\hat{\boldsymbol{\varsigma}}\left(\mathbf{x}_{s}^{d}\right)=\sum_{p=1}^{D} \mathbf{C}_{p} \phi\left(\left\|\mathbf{x}_{s}^{d}-\mathbf{x}_{p}^{d}\right\|\right) \quad 1 \leq s \leq D
\end{gathered}
$$

To generate the CFD mesh of the damaged geometry, Eq. (1) is used to map the deformation calculated between the undamaged and damaged blade profiles onto the undamaged CFD mesh. The points that define the undamaged blade profiles are chosen as the driver points, and the deformation vector at each driver point is determined by calculating the difference between the points on the undamaged blade profiles and the corresponding points on the damaged profiles. The deformation is constrained at the inflow, outflow, hub, and shroud to preserve the profiles of these surfaces in the $(r, z)$ plane. Cross-sections of the undamaged and damaged CFD mesh at $75 \%$ span are shown in Figs. 4 .

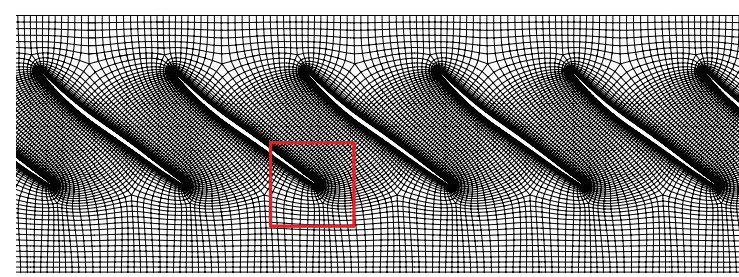

(a) Undamaged CFD mesh.

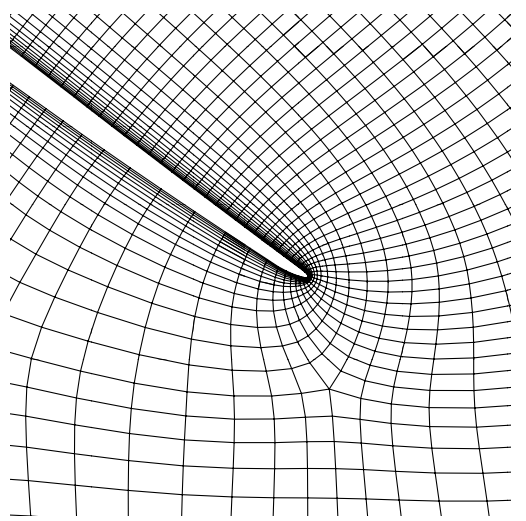

(c) Undamaged blade 2 leading edge CFD mesh.

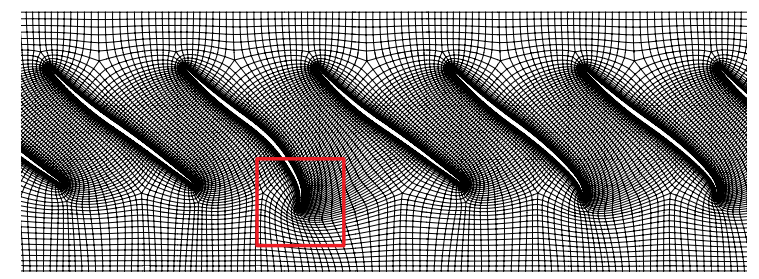

(b) Damaged CFD mesh.

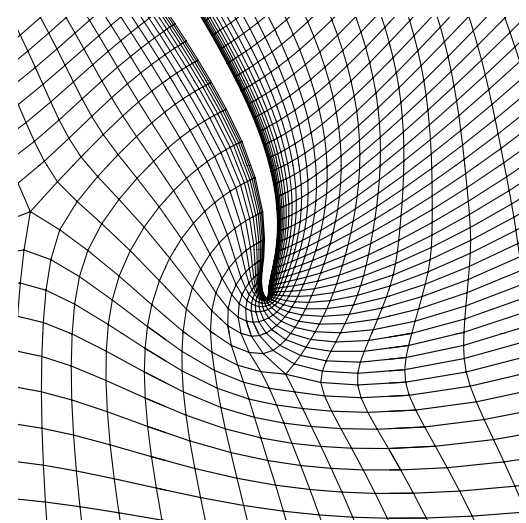

(d) Damaged blade 2 leading edge CFD mesh.

Figure 4: Comparison of the undamaged and damaged CFD mesh at $75 \%$ span. 


\section{Boundary Conditions}

At the domain inflow, the total pressure, total temperature, turbulence intensity, and flow direction of the incoming flow that correspond to a particular flight condition are enforced. The total pressure distribution includes flow losses due to the upstream engine inlet nacelle. At the core duct outflow, the mass flow rate is specified with the assumption that the engine core "pulls" a fixed mass flow rate through the core duct for a given operating condition (free-stream condition and engine rotation speed). Static pressure is enforced at the bypass duct outflow using a radial-equilibrium condition that permits the static pressure to vary radially while maintaining the specified static pressure on average. Solid wall boundary conditions are enforced at the fan blades, hub, shroud, and splitter such that the velocity of the flow matches that of the wall through specification of a no-slip condition. A zero wall velocity is prescribed at the shroud and splitter, and a non-zero wall velocity that results from engine rotation is prescribed at the blades and hub.

\section{Operating Condition}

The performance of a fan stage is characterized by the total pressure ratio and referred mass flow rate. The total pressure ratio is defined as the ratio of the mass flow averaged total pressure at the bypass duct outflow to the mass flow averaged total pressure just upstream of the fan blades. The referred mass flow rate, calculated using Eq. (3), is the mass flow rate through the domain corrected for non-standard day inflow conditions and represents the mass flow that would pass through the fan if the inflow total pressure and total temperature corresponded to standard day conditions. The operating point of a fan stage is described by the total pressure ratio and referred mass flow rate resulting from operation at a particular operating condition defined by the engine rotation speed, inflow conditions, and outflow static pressure. The inflow total pressure and total temperature correspond to free-stream conditions, and the outflow static pressure represents the back-pressure produced by downstream engine components.

$$
\dot{m}_{R}=\dot{m} \sqrt{\frac{T}{T_{S T D}}}\left(\frac{P_{S T D}}{P}\right)
$$

A fan map depicts the operating points obtained using numerical simulations and experimental tests of an isolated fan stage for a variety of operating conditions. The operating points obtained with various outflow static pressures at a fixed engine speed and inflow conditions are connected to form characteristic curves. The stall point is identified by the peak in total pressure ratio along a characteristic curve and indicates the onset of stall. Stall is an undesirable, unsteady flow phenomena produced by flow separation that typically occurs at low mass flow rates and high bypass duct static pressure. A stall line connects the stall points on each characteristic curve and identifies the boundary of steady flow, where operating points to the left of the stall line are unsteady. A fan map also includes the fan operating line that consists of the unique set of operating points produced by the fan stage when installed in a complete engine. The operating line is measured during an infinitesimally slow throttle sweep of a complete-engine operating at a particular free-stream condition. A representative fan map that includes several characteristic curves, the associated stall points, and the stall line is shown in Fig. 5 .

For proper representation of the fan operating in a complete engine using a CFD model of an isolated fan stage, a bypass duct static pressure boundary condition is specified so that the predicted operating point coincides with a point on the operating line. The bypass duct static pressure necessary to achieve the desired operating point at the intersection of the characteristic curve and the operating line is unknown a priori. Therefore, an iterative procedure is utilized to map the characteristic curve and determine the bypass duct static pressure that yields an operating point within $1 \%$ error of the operating line. The error is calculated using Eq. (4) where the predicted operating point is denoted by $\left(\overline{\dot{m}}_{R}, \overline{P R}\right)$, and $\Delta \dot{m}_{R}$ and $\Delta P R$ denote the horizontal and vertical distance of the operating point from the operating line, as shown in Fig. 5 .

$$
\% \Delta \mathrm{OL}=\sqrt{\left(\frac{\Delta \dot{m}_{R}}{\overline{\dot{m}}_{R}}\right)^{2}+\left(\frac{\Delta P R}{\overline{P R}}\right)^{2}} \times 100
$$

\section{Structural Dynamic Model}

The structural dynamic model is implemented using ANSYS Mechanical APDL, a commercial FEMbased structural dynamics solver. The computational domain for the structural dynamic model consists of 


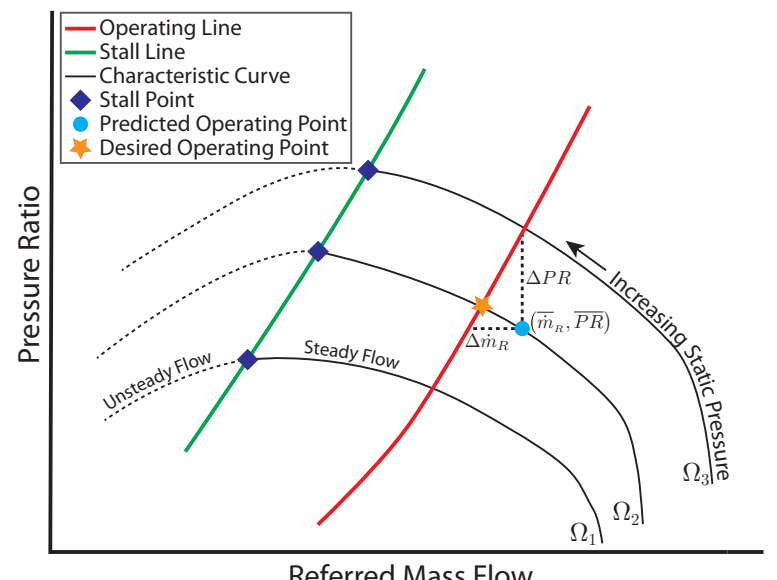

Figure 5: Representative fan map.

24 individual blades each cantilevered at the blade root. The hub disk is not modeled since its flexibility is assumed to be insignificant compared to that of the fan blades. The fan blade material is titanium and is modeled with a linearly elastic material law.

\section{A. Computational Mesh}

The structural mesh follows a structured topology such that the structural elements on the wetted surface of the blade completely overlap with the CFD mesh at the blade surface. The structural mesh also features a curved leading edge and trailing edge to aid in load and displacement transfer between the structural and aerodynamic meshes. The fan blades are modeled using 8-noded, solid, hexahedral elements (ANSYS SOLID185 element type) with three translational degrees of freedom at each node. A mesh sensitivity was conducted to identify the mesh resolution suitable for the objections of this study. The structural mesh utilized in this study consists of 5712 nodes and 4020 elements per blade for a total of 137,088 nodes and 96,480 elements. Figure 6(a) shows the structural mesh of an undamaged blade. Figure 6(b) shows the computational mesh of the damaged fan, where the damaged blades are highlighted in orange.

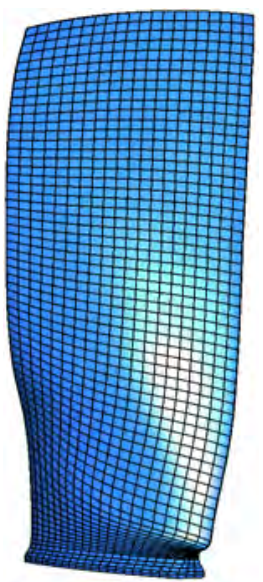

(a) Structural mesh for an undamaged blade.

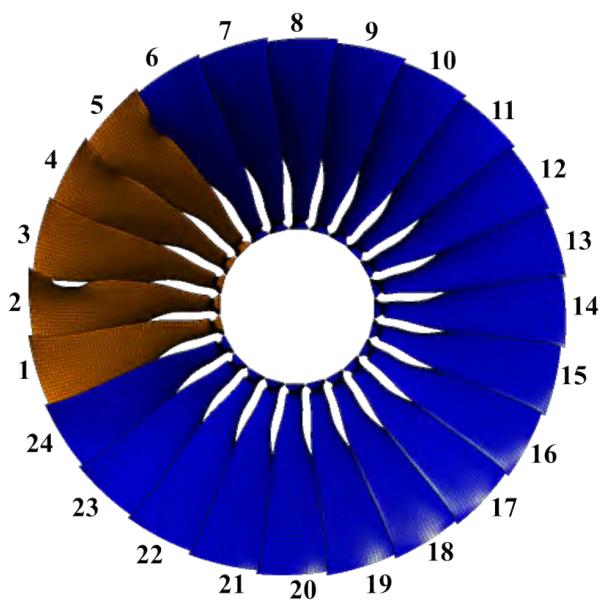

(b) Bird-damaged structural mesh with damaged blades highlighted in orange.

Figure 6: Structural mesh for the damaged fan. 


\section{B. Rotating Mode Shapes}

The first 5 mode shapes of a rotating, undamaged fan blade at take-off engine rotational speed are shown in Figs. 7. The natural frequencies of the first 5 mode shapes are listed in Table 2, The mode shapes of the damaged blades are similar to those of the undamaged blade, and the rotating natural frequencies for each damaged blade are provided in Table 2 .

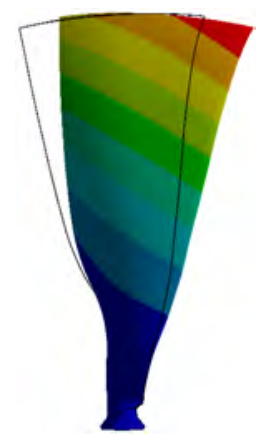

(a) 1st bending.

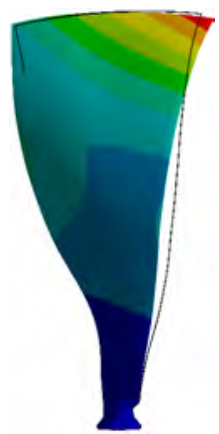

(b) 2nd bending.

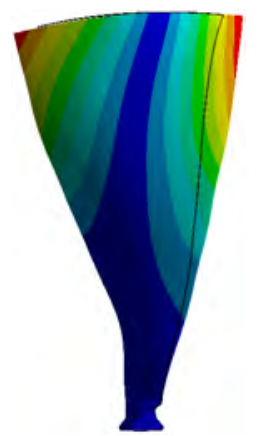

(c) 1 st torsion.

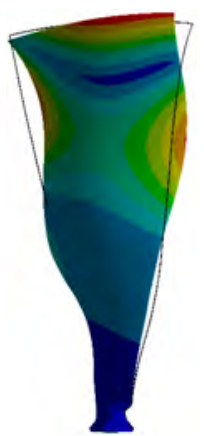

(d) 3rd bending.

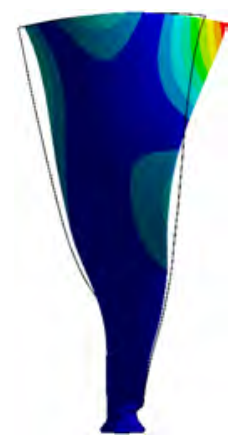

(e) 2nd torsion.

Figure 7: First 5 mode shapes of a rotating, undamaged blade.

Table 2: Natural frequencies of the first 5 modes of the rotating undamaged and damaged blades.

\begin{tabular}{l||c|c|c|c|c} 
& $\begin{array}{c}\text { 1st Bending } \\
(1 \mathrm{~B})\end{array}$ & $\begin{array}{c}\text { 2nd Bending } \\
(\text { 2B })\end{array}$ & $\begin{array}{c}\text { 1st Torsion } \\
(\text { 1T })\end{array}$ & $\begin{array}{c}\text { 3rd Bending } \\
(3 \mathrm{~B})\end{array}$ & $\begin{array}{c}\text { 2nd Torsion } \\
(2 \mathrm{~T})\end{array}$ \\
\hline \hline Undamaged & $126.97 \mathrm{~Hz}$ & $262.95 \mathrm{~Hz}$ & $381.21 \mathrm{~Hz}$ & $532.65 \mathrm{~Hz}$ & $712.65 \mathrm{~Hz}$ \\
Blade 1 & $126.98 \mathrm{~Hz}$ & $263.61 \mathrm{~Hz}$ & $373.44 \mathrm{~Hz}$ & $537.52 \mathrm{~Hz}$ & $699.62 \mathrm{~Hz}$ \\
Blade 2 & $126.70 \mathrm{~Hz}$ & $264.81 \mathrm{~Hz}$ & $301.22 \mathrm{~Hz}$ & $574.09 \mathrm{~Hz}$ & $656.77 \mathrm{~Hz}$ \\
Blade 3 & $127.00 \mathrm{~Hz}$ & $263.69 \mathrm{~Hz}$ & $374.25 \mathrm{~Hz}$ & $534.29 \mathrm{~Hz}$ & $717.84 \mathrm{~Hz}$ \\
Blade 4 & $126.85 \mathrm{~Hz}$ & $263.37 \mathrm{~Hz}$ & $330.25 \mathrm{~Hz}$ & $560.51 \mathrm{~Hz}$ & $654.37 \mathrm{~Hz}$ \\
Blade 5 & $127.03 \mathrm{~Hz}$ & $264.11 \mathrm{~Hz}$ & $339.39 \mathrm{~Hz}$ & $560.24 \mathrm{~Hz}$ & $677.24 \mathrm{~Hz}$
\end{tabular}

\section{Equations of Motion}

The equations of motion solved by ANSYS Mechanical APDL are derived from the principle of virtual work. The mass and stiffness matrices are assembled for the entire structural mesh using standard methods, and the assembled deformation vector, $\mathbf{U}$, contains the translational degrees of freedom for each node. The final equation of motion is given by Eq. (5), where $\mathbf{F}_{\boldsymbol{\Omega}}$ accounts for the centrifugal effects due to engine rotation. The assembled force vector, $\mathbf{F}_{\text {aero }}$ represents the aerodynamic force transferred from the CFD mesh to the structural mesh.

$$
\mathbf{M} \ddot{\mathbf{U}}+\mathbf{K}(\mathbf{U}) \mathbf{U}=\mathbf{F}_{\boldsymbol{\Omega}}+\mathbf{F}_{\text {aero }}
$$

The structural dynamic model includes a large deflection formulation to accommodate changes in the stiffness matrix that result from structural deformation. Therefore, the equations of motion represent a nonlinear set of equations where the stiffness matrix is a function of the deformation vector, $\mathbf{K}=f(\mathbf{U})$. A Newton-Raphson iterative procedure is implemented to update the stiffness matrix within each time-step. A description of the Newton-Raphson algorithm that is utilized by ANSYS Mechanical APDL is provided in the ANSYS Mechanical APDL Theory Reference Guide.27

The HHT- $\alpha$ time-integration scheme is used to solve Eq. (5) in time. The HHT- $\alpha$ is an extension of the Newmark time-integration method that damps out spurious high-frequency response by introducing controllable numerical dissipation in higher frequency modes while maintaining second-order accuracy 28 HHT- $\alpha$ is unconditionally stable and second-order accurate if the parameters meet the criteria described by Eqs. (6)-(8). For this study, the ANSYS default values for the HHT- $\alpha$ formulation are used: $\gamma=0.6$, 
$\beta=0.3025$, and $\alpha=0.1$. Further details on the HHT- $\alpha$ scheme and its implementation are provided in the ANSYS Mechanical APDL Theory Reference Guide.27

$$
\begin{array}{r}
\gamma=1 / 2+\alpha \\
\beta=(1+\alpha)^{2} / 4 \\
0 \leq \alpha \leq 1 / 3
\end{array}
$$

\section{Coupled Fluid-Structure Framework}

The ANSYS Multi-field solver is used to couple the ANSYS CFX aerodynamic solver and ANSYS Mechanical APDL structural solver. The computational frameworks and coupling algorithm for the one-way and fully-coupled fluid-structure interaction calculations are provided next. Further information is available in the ANSYS documentation. ${ }^{29}$

\section{A. One-way Forced Response Framework}

For the one-way forced response calculation, the unsteady aerodynamic loads are calculated and applied to the structural model at each time-step to obtain the structural response. The CFD mesh is not deformed with the structure, and the feedback mechanism of the structural response on the unsteady aerodynamic loading is not captured. The aerodynamic load for the forced response varies with time and only depends on the transient effects of the aerodynamic calculations. Equation (9) provides the equations of motion for the forced response calculations.

$$
\mathbf{M} \ddot{\mathbf{U}}+\mathbf{K}(\mathbf{U}) \mathbf{U}=\mathbf{F}_{\boldsymbol{\Omega}}+\mathbf{F}_{\text {aero }}(t)
$$

A flow chart of the forced response framework is shown in Fig. 8. The mapping between the hot FEM mesh and the CFD mesh at the wetted surface is performed first to establish the fluid structure interface (FSI). Next, a steady-state CFD calculation is carried out to generate the initial conditions for the unsteady CFD calculations needed for the forced response calculation. During each time-step of the forced response calculation, the aerodynamic loads from the unsteady CFD analysis are transferred to the surface of the FEM mesh and the structural dynamic response is calculated.

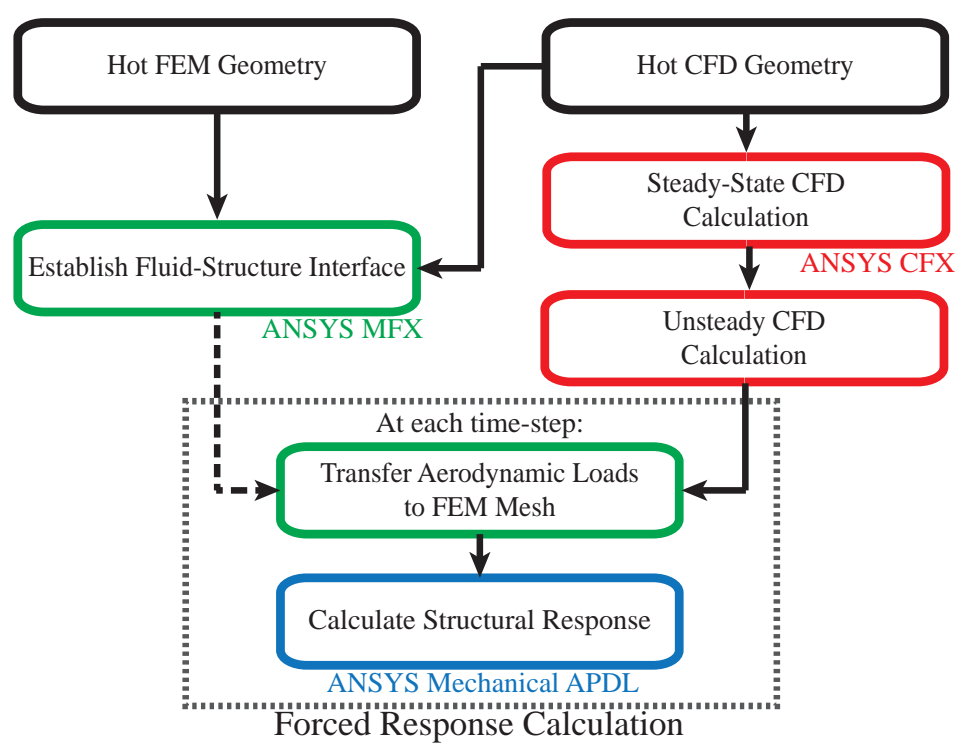

Figure 8: Flow chart of the forced response framework. 


\section{B. Fully-Coupled Aeroelastic Framework}

For the aeroelastic calculations, an implicit coupling algorithm is implemented where the aerodynamic and structural models are solved iteratively within each time-step. The CFD mesh is deformed with the structure such that the time-varying displacement at the blade surface influences the aerodynamic loads on the structure. Equation (10) provides the equations of motion for the aeroelastic calculations.

$$
\mathbf{M} \ddot{\mathbf{U}}+\mathbf{K}(\mathbf{U}) \mathbf{U}=\mathbf{F}_{\boldsymbol{\Omega}}+\mathbf{F}_{\text {aero }}(t, \mathbf{U}, \dot{\mathbf{U}}, \ddot{\mathbf{U}})
$$

A flow chart of the aeroelastic framework is shown in Fig. 9. The mapping between the hot FEM mesh and the CFD mesh is performed to establish the FSI at the wetted surface. Next, the aerodynamic forces from a steady-state CFD calculation of the damaged fan are applied to a static structural model to initialize the aerodynamic and structural dynamic models for the aeroelastic response calculations. Within each time-step of the aeroelastic response calculation, the aerodynamic state is updated and the associated aerodynamic loads are transferred to the structural mesh. The resulting structural displacements are then transferred to the CFD mesh at the blade surface and the CFD nodes are displaced due to the blade motion.

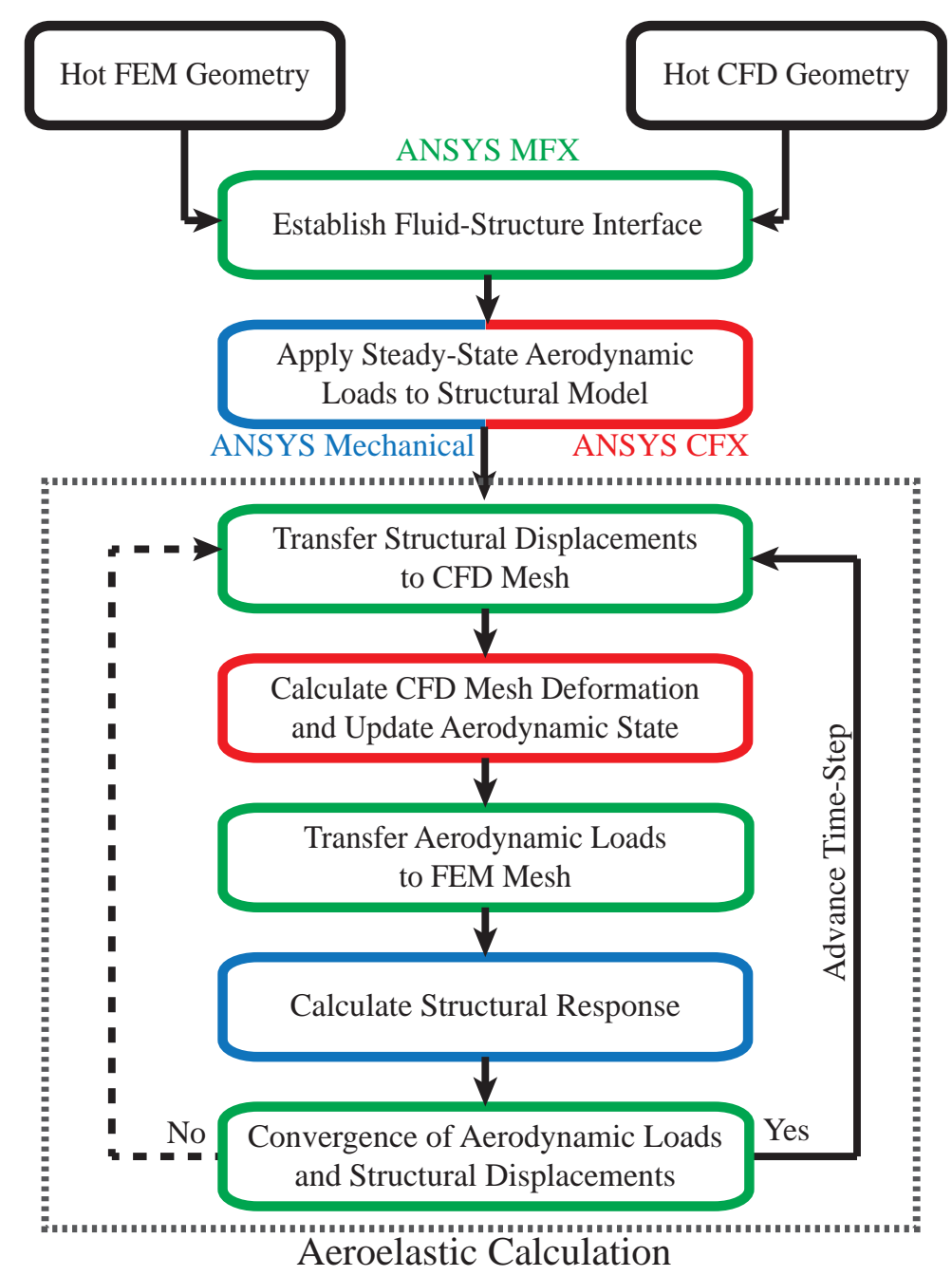

Figure 9: Flow chart of the aeroelastic framework.

Several coupling sub-iterations are performed within each physical time-step to ensure convergence of the aerodynamic loads and structural displacements that is required for an implicit solution. Convergence occurs when the changes in loads and displacements between the current and previous sub-iteration is smaller than a specified tolerance level. Equation (11) provides the convergence criteria, where $\|$ || indicates the 
$\mathrm{L}^{2}$-norm and the CFX default convergence tolerance of $\varepsilon=0.01(1 \%)$ is specified.

$$
\frac{\log \left(\left\|\boldsymbol{\varphi}_{\text {new }}-\boldsymbol{\varphi}_{\mathrm{old}}\right\| /\left\|\boldsymbol{\varphi}_{\mathrm{new}}\right\|\right)-\log (\varepsilon)}{1-\log (\varepsilon)} \leq 0
$$

\section{Aerodynamic Load and Structural Deformation Transfer}

For both the forced response and aeroelastic calculations, the aerodynamic forces are transferred from the CFD mesh to the FEM mesh at the FSI of the fan blade to obtain $\mathbf{F}_{\text {aero }}$ in Eq. (5). Within ANSYS CFX, the aerodynamic forces are first calculated at each CFD node on the blade surface using Eq. (12) and include contributions from the aerodynamic pressure and viscous wall shear stresses. Next, the forces are transferred from the CFD nodes to the FEM nodes on the blade surface using the conservative interpolation scheme available in ANSYS MFX.

$$
\mathbf{Q}^{j}(t)=\int_{S}(p(t)+\tau(t)) \cdot \mathbf{n} d S
$$

For the aeroelastic calculations, the structural displacements are transferred from the FEM mesh to the CFD mesh using the profile-preserving interpolation scheme available in ANSYS MFX. Each CFD node on the blade surface is mapped to a FEM element on the blade surface, and the shape functions of the associated FEM element are used to interpolate the displacement at each CFD node. This interpolation scheme preserves the local distributions of displacements transferred from the coarse FEM mesh to the fine CFD mesh.

The mesh displacement is prescribed on the blade surface based on the structural displacement and is set to zero on the inlet, outlet bypass, outlet core, and splitter surfaces. The CFD nodes on the hub and shroud are allowed to slide on the boundaries so that the original surfaces of revolution are retained. The displacement of the interior CFD nodes is governed by the displacement-diffusion equation provided by Eq. (13). In Eq. (13), $\Gamma$ is the mesh diffusivity, which is analogous to the mesh stiffness, and $\boldsymbol{\delta}$ is the mesh displacement relative to the mesh at the previous time-step.

$$
\nabla \cdot(\Gamma \nabla \boldsymbol{\delta})=0
$$

A spatially dependent mesh diffusivity is useful for preserving the initial mesh distribution and element quality. A large mesh diffusivity restricts movement of the nodes relative to each other such that regions of lower mesh diffusivity absorb a larger amount of the mesh displacement. A mesh diffusivity that is inversely proportional to the element volume is specified so that the larger elements in the blade passages absorb a majority of the displacement and the small elements near the blade surface do not become highly distorted. Equation (14) provides the expression for mesh diffusivity.

$$
\Gamma=\left(\frac{\Lambda_{\text {ref }}}{\Lambda}\right)^{2}
$$

\section{Results}

The steady-state and unsteady aerodynamic behavior of a bird-damaged fan is presented in this section. Subsequently, the forced response and aeroelastic response calculations of a bird-damaged fan are presented and compared. The unsteady aerodynamic and forced-response calculations are an extension of those presented in Ref. 20, and the fully-coupled aeroelastic calculations are a new contribution of this study.

\section{A. Aerodynamic Calculations of the Damaged Fan}

Steady-state and unsteady aerodynamic calculations are examined to provide insight into the aerodynamic behavior of a bird-damaged fan. The freestream conditions correspond to standard day $+27^{\circ} \mathrm{F}$ conditions, the engine rotational speed is set to take-off speed, and the flight Mach number is zero. In Ref. 19, steady-state aerodynamic calculations performed with the aerodynamic model were verified against data from industry for an undamaged and damaged fan. 


\section{Steady-State Aerodynamic Calculations}

The characteristic curve of the damaged fan was first mapped to identify the operating point within $1 \%$ error of the fan operating line. The fan operating line together with the damaged fan characteristic curve and the damaged fan operating point are shown in Fig. 10, where the values are normalized by the referred mass flow rate and total pressure ratio of an undamaged fan. The operating point is significantly influenced by the bird damage. The total pressure ratio decreases by $7.5 \%$ and the referred mass flow decreases by $8.2 \%$, where the mass flow loss is directly related to the thrust loss resulting from the bird-strike. The characteristic curve indicates that the bird-damaged fan is operating near the stall point, as identified by the peak in total pressure. This implies that unsteady flow can influence the aerodynamic behavior of the bird damaged fan to a significant extent.

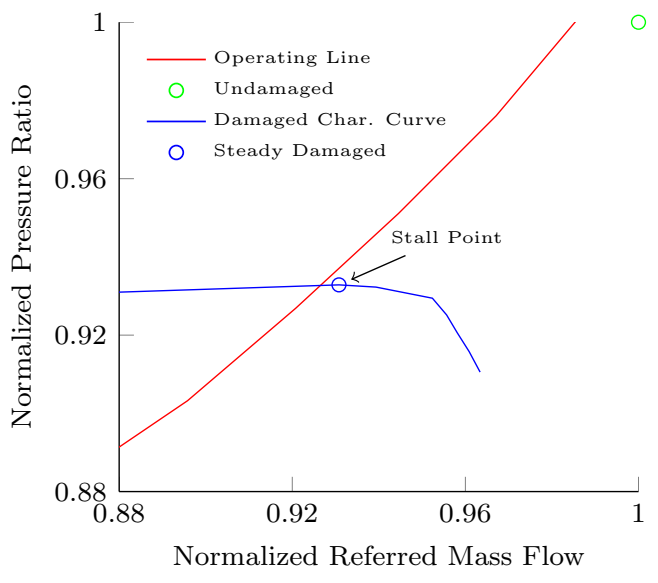

Figure 10: Normalized fan map.

Mach number contours on a constant-axial slice of the wheel at mid blade chord are shown in Figs. 11 . for the undamaged and damaged fans. The significant effect of the damaged sector on the aerodynamic environment of the entire fan wheel is evident. The damaged sector produces stalled flow, identified by the blue regions in Fig. 11(b), for a large spanwise portion of the damaged blade passages. Stalled flow is also present at the undamaged blade tips for roughly half of the fan wheel, from blades 17 to 5 . The flow loss associated with the stalled blade tips is compensated by the increased flow through the unstalled blade passages, as is evident by the increased Mach number distribution through these blade passages.

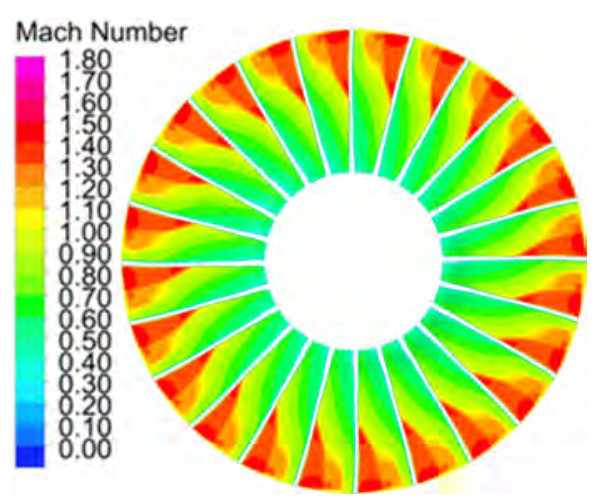

(a) Undamaged fan Mach number contour at mid-chord (direction of rotation: clockwise).

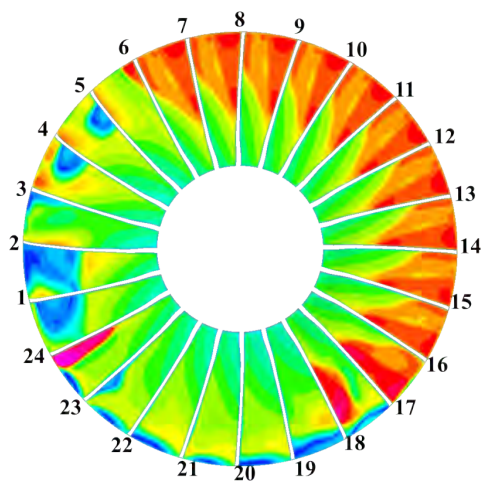

(b) Damaged fan Mach number contour at mid-chord (direction of rotation: clockwise).

Figure 11: Undamaged and damaged fan Mach number contours. 


\section{Unsteady Aerodynamic Calculations}

The unsteady aerodynamic calculations are initialized from the steady-state solution. A physical time-step of $\Delta t=\frac{1}{500 \Omega}$ is specified, and 3 sub-iterations are performed at each time-step to ensure convergence of the solution. The unsteady calculations were performed for 5,000 time-steps corresponding to 10 revolutions of the fan.

The total pressure ratio and referred mass flow rate, normalized by the undamaged fan referred mass flow rate and total pressure ratio, are shown in Fig. 12(a) as a function of the fan revolution. Considerable unsteadiness in the operating point is apparent. The referred mass flow rate varies $\pm 3.0 \%$ about its mean value and the total pressure ratio varies $\pm 1.3 \%$ about its mean value. The unsteady operating point, plotted on the fan map in Fig. 12(b), oscillates below the steady-state operating point indicating that unsteadiness contributes to additional flow losses.

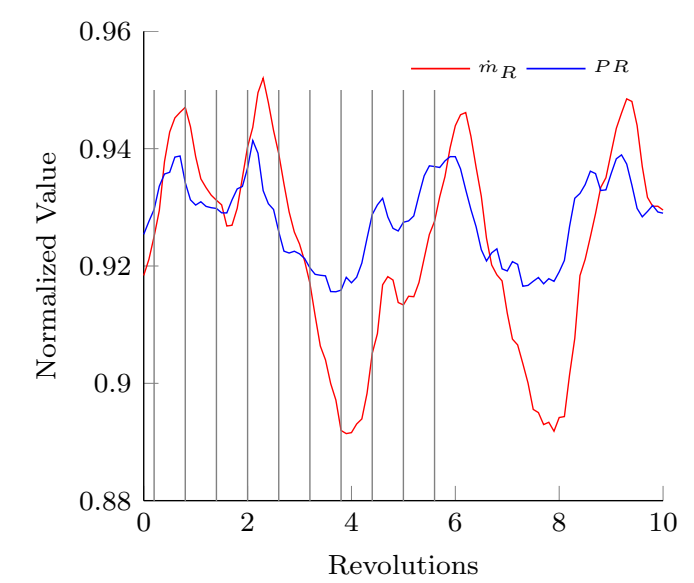

(a) Referred mass flow rate and total pressure ratio time history.

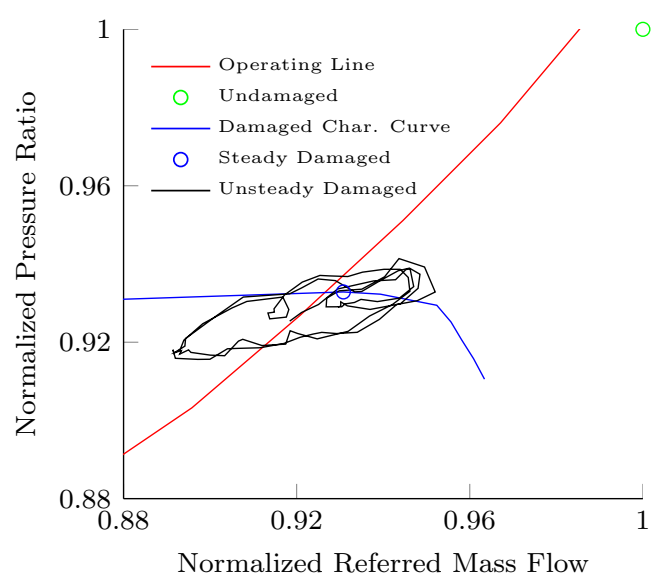

(b) Fan map with characteristic curve and steady and unsteady operating points.

Figure 12: Unsteady total pressure ratio and referred mass flow rate.

Unsteady Mach number contours at the mid-chord are shown in Figs. 13(a) $13(\mathrm{j})$ for 10 equally spaced time-steps spanning the first 5.6 revolutions of the unsteady calculation. The corresponding total pressure ratio and referred mass flow rate at these time-steps are indicated by the fine vertical lines in Fig. 12(a). Limited flow unsteadiness is evident in the vicinity of the damaged blades. In contrast, significant unsteadiness is apparent in much of the undamaged sector, with the greatest level of flow unsteadiness occurring in the blade passages between blade 16 and blade 21 .

The stalled flow emanating from the damaged sector, denoted a stall cell and identified by the blue regions, is the dominant unsteady flow effect in Figs. 13. In Fig. 13(b), the stall cell covers roughly a third of the fan wheel, from blade 21 to blade 5, and the mass flow rate is near its maximum. From Fig. 13(c) to $13(\mathrm{~g})$, the stall cell regresses slightly before propagating opposite the direction of rotation until half of the blade tips are stalled, from blade 15 to blade 5. At this point, the mass flow rate is at a minimum due to the partially blocked blade passages associated with the stalled flow. Subsequently from Fig. 13(h) to 13(j). the stall cell detaches from the damaged sector, progresses opposite the direction of rotation, and dissipates as the flow recovers and the mass flow rate increases to the maximum value. In addition, as the stall cell propagates at the blade tips, the Mach number in the inner span of the corresponding blade passage also decreases, indicating a loss of mass flow through a majority of the blade passages.

\section{B. Forced Response of the Damaged Fan}

The forced response calculations of the bird damaged fan are presented in this section. The time-dependent aerodynamic loads are extracted from the unsteady CFD calculations and transferred to the structural solver at each time-step using the one-way forced response framework. The forced response calculations were performed for 5,000 time-steps corresponding to 10 revolutions of the fan. The circumferential displacement, $u_{\theta} R$, at the leading edge of the blade tips is used as an indicator of the blade response. The displacement is 


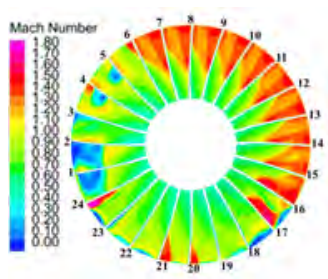

(a) 0.2 revolutions.

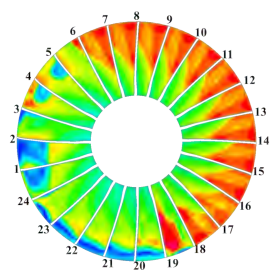

(f) 3.2 revolutions.

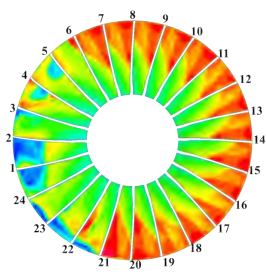

(b) 0.8 revolutions.

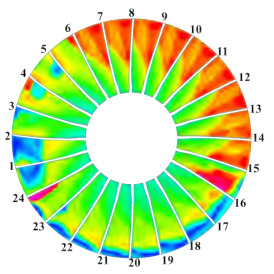

(g) 3.8 revolutions.

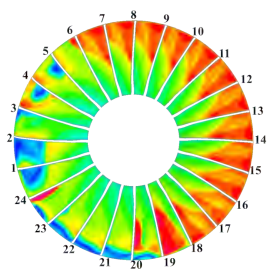

(c) 1.4 revolutions.

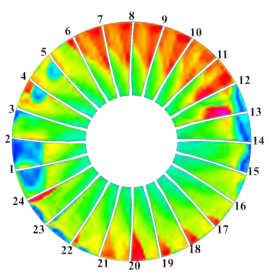

(h) 4.4 revolutions.

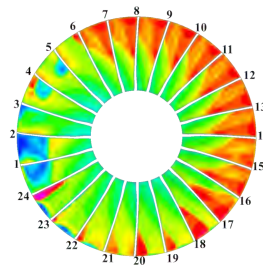

(d) 2.0 revolutions.

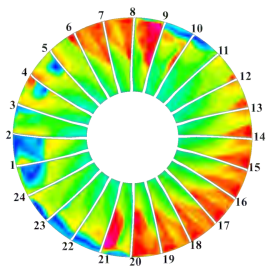

(i) 5.0 revolutions.

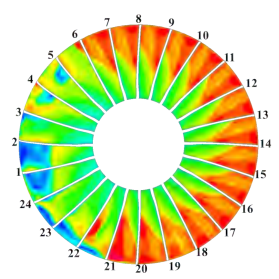

(e) 2.6 revolutions.

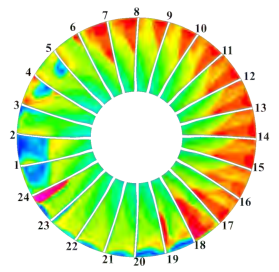

(j) 5.6 revolutions.

Figure 13: Unsteady Mach number contours of the damaged blade at mid-chord (direction of rotation: clockwise).

calculated relative to the steady-state configuration in which rotational velocity and steady-state CFD loads have been introduced.

Figures 14 show the tip displacement for the duration of the forced response calculations, where blades with similar responses are grouped together. The tip displacements for blades 15-21, shown in Fig. 14(c), are the greatest and result from the large aerodynamic loads produced by the unsteady stall cell in this region of the fan. The peak amplitudes of the tip displacements for these blades grow for the 10 revolutions that were calculated; however, further calculations will be performed to determine whether this behavior continues. The tip displacements for blades 7-14, shown in Fig. 14(b) exhibit a limited structural response for the first 4 revolutions until the stall cell releases from the damaged sector and progresses through this region of the fan yielding a sudden increase in tip displacement. This behavior is repeated at $\sim 8$ fan revolutions when a second stall cell is released and progresses through this region. By comparison, blades 22-24, which are located immediately downstream of the damaged sector, exhibit smaller tip displacements that remain bounded with time, as shown in Fig. 14(d). Finally, the tip displacements of the damaged blades 1-5, shown in Fig. 14(a) and the undamaged blade immediately upstream of the damaged sector are the smallest, with blade 4 exhibiting the largest response of the damaged blades. Overall, the most significant structural response occurs for the blades downstream of the damaged sector due to the progression of the stall cell emanating from the damaged sector.

To determine modal participation in the structural response, the blade displacements are projected into modal coordinates using Eq. (15). During post-processing of the structural response, Eq. 15. is solved at each time-step using a least squares approach to determine the generalized degrees of freedom, $q_{m}$ corresponding to each mode shape. The first 10 natural modes of each rotating blade are used and the mode shapes are normalized by the magnitude of the leading edge tip displacement. Equation 16 is then used to calculate the contribution of the $m^{\text {th }}$ natural mode to the displacement of any node in the FEM mesh.

$$
\begin{aligned}
& \mathbf{U}(\mathbf{x}, t) \approx \sum_{m=1}^{10} q_{m}(t) \boldsymbol{\Phi}_{m}(\mathbf{x}) \\
& \mathbf{U}_{m}(\mathbf{x}, t)=q_{m}(t) \boldsymbol{\Phi}_{m}(\mathbf{x}, t)
\end{aligned}
$$

The circumferential displacement together with the contributions from the first 5 natural modes are shown in Figs. 15 for one blade that best represents the blade response from each group in Figs. 14 . The contribution from the remaining natural modes is negligible and is not shown. The tip displacement of blade 5, shown in Fig. 15(a) is dominated by the first bending mode and includes a small contribution from the first torsion mode that decays in time. The tip displacement of blade 12, shown in Fig. 15(b) is dominated 


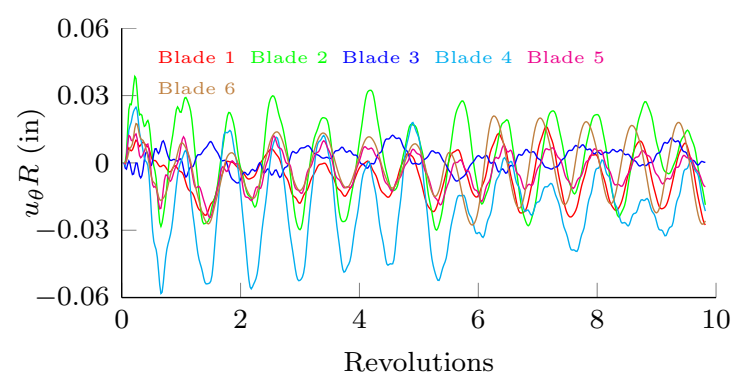

(a) Relative tip displacements for blades 1-6.

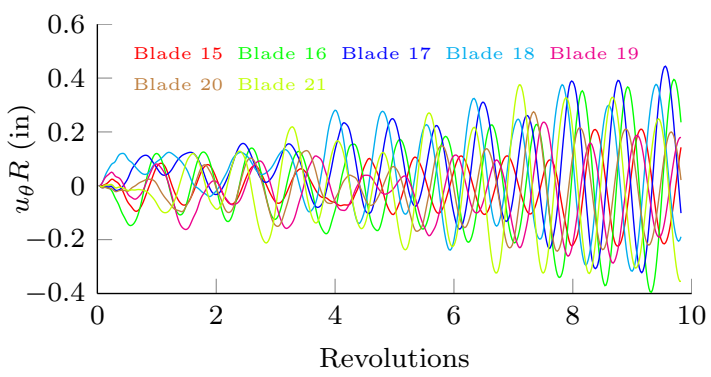

(c) Relative tip displacements for blades 15-21.

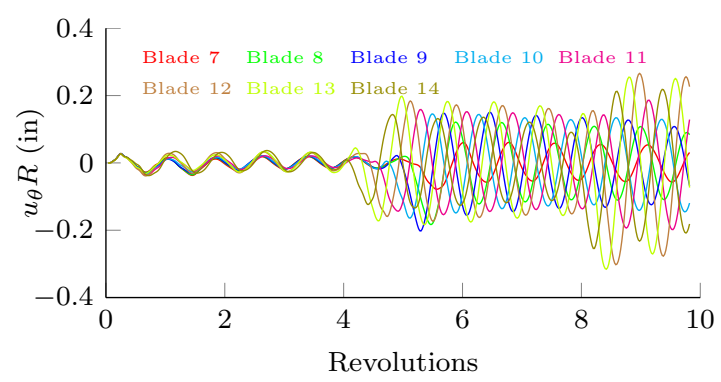

(b) Relative tip displacements for blades 7-14.

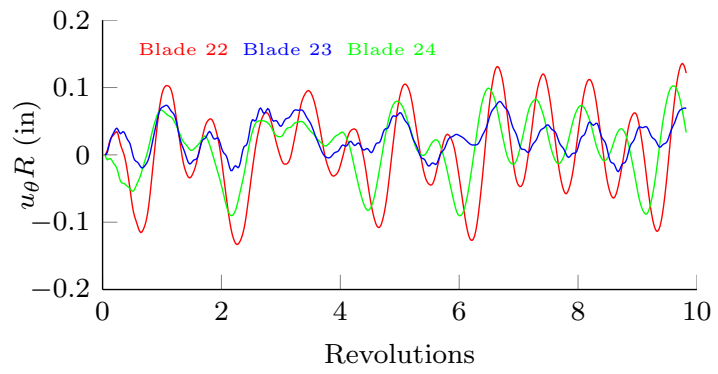

(d) Relative tip displacements for blades 22-24.

Figure 14: Forced response tip displacements, relative to the steady-state configuration.

by the first bending mode and decays slightly in time following the jumps in structural response at $\sim 4$ and $\sim 8$ revolutions. The tip displacement of blade 16 grows in time with the first bending mode dominating the response, as shown in Fig. 15(c), The response of blade 24, shown in Fig. 15(d) is also dominated by the first bending mode combined with a slight contribution from the second torsion mode that exhibits a "beating" behavior. Table 3 summarizes the modal contribution for the forced response and aeroelastic response of blades 1-24. In Table 3 , bold face type indicates the dominant modes, $\downarrow$ indicates a decaying mode, $\uparrow$ indicates a growing mode, and * indicates a mode whose amplitude displays a "beating" behavior. Overall, the first bending mode dominates the response of all blades, and the small contributions from other modes either decay in time or exhibit a "beating" behavior.

Table 3: Modal contributions of the first 5 natural modes for blades 1-24.

\begin{tabular}{c||c|c} 
Blade & Forced Response & Aeroelastic Response \\
\hline Blade 1 & $\mathbf{1 B}$ & $\mathbf{1 B}, \mathbf{2 T} \uparrow$ \\
Blade 2 & $\mathbf{1 B}, 1 \mathrm{~T} \downarrow$ & $\mathbf{1 B}, 1 \mathrm{~T} \uparrow, 2 \mathrm{~T} \uparrow$ \\
Blade 3 & $\mathbf{1 B}, 2 \mathrm{~T}^{*}$ & $\mathbf{1 B}, \mathbf{2} \mathbf{T}^{*}$ \\
Blade 4 & $\mathbf{1 B}, 1 \mathrm{~T} \downarrow, 2 \mathrm{~T}^{*}$ & $\mathbf{1 B}, \mathbf{2} \mathbf{T}^{*}$ \\
Blade 5 & $\mathbf{1 B}, 1 \mathrm{~T} \downarrow, 2 \mathrm{~T}^{*}$ & $\mathbf{1 B}, \mathbf{2 T} \uparrow$ \\
Blade 6 & $\mathbf{1 B}$ & $\mathbf{1 B}$ \\
Blades 7-18 & $\mathbf{1 B} \uparrow$ & $\mathbf{1 B} \uparrow$ \\
Blade 19 & $\mathbf{1 B}$ & $\mathbf{1 B}, 2 \mathrm{~T} \uparrow$ \\
Blades $20-21$ & $\mathbf{1 B}$ & $\mathbf{1 B} \downarrow, 2 \mathrm{~T} \uparrow$ \\
Blade 22 & $\mathbf{1 B}$ & $\mathbf{1 B}, 2 \mathrm{~T} \uparrow$ \\
Blade 23 & $\mathbf{1 B}$ & $\mathbf{1 B} \downarrow, 2 \mathrm{~T} \uparrow$ \\
Blade 24 & $\mathbf{1 B}, 2 \mathrm{~T}^{*}$ & $\mathbf{1 B}, \mathbf{2} \mathbf{T}^{*}$
\end{tabular}




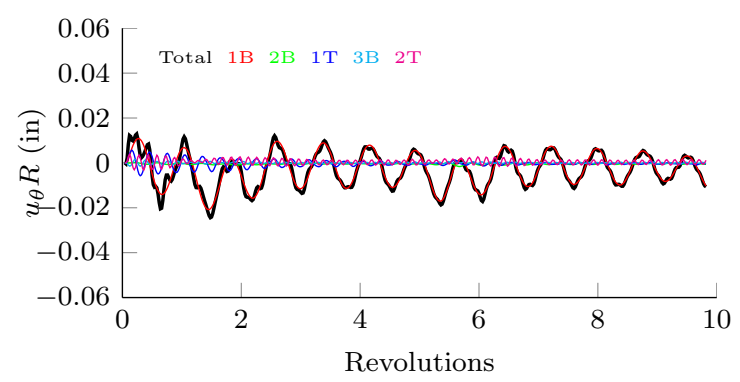

(a) Relative tip displacements for blade 5 .

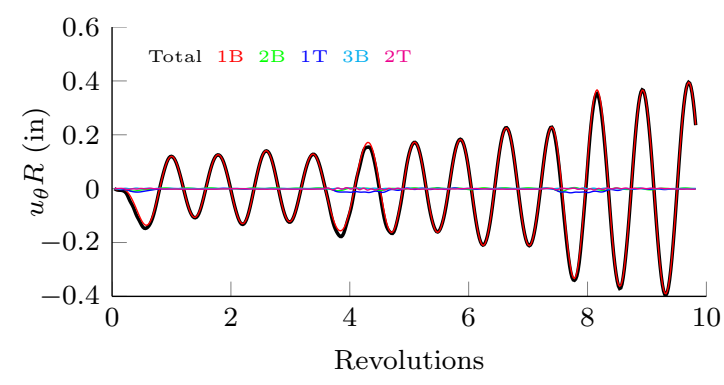

(c) Relative tip displacements for blade 16 .

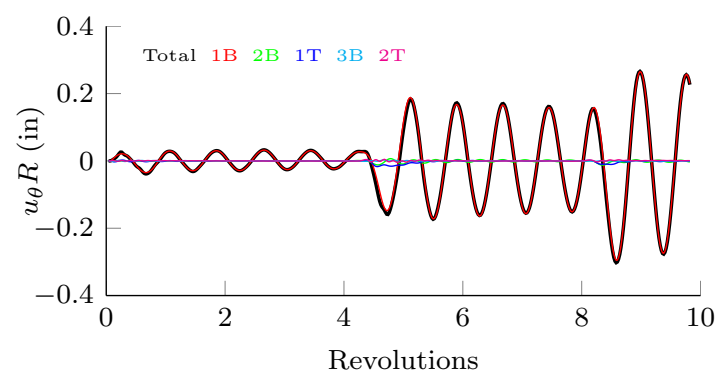

(b) Relative tip displacements for blade 12 .

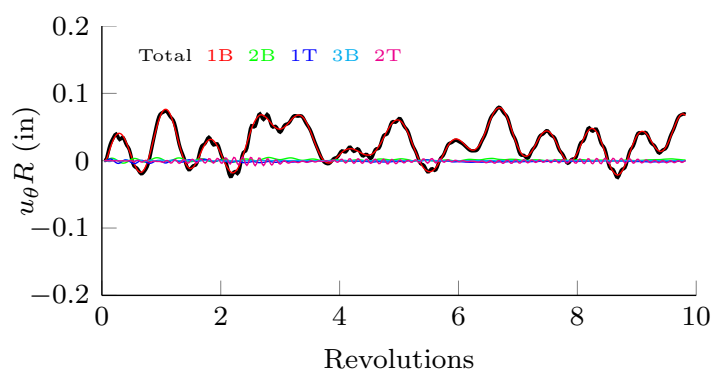

(d) Relative tip displacements for blade 24 .

Figure 15: Forced response tip displacements and the modal contributions of the first 5 natural modes.

\section{Aeroelastic Response of the Damaged Fan}

The aeroelastic response calculations of the bird damaged fan are presented in this section. The aerodynamic and structural models are solved iteratively within each time-step using the fully-coupled aeroelastic framework. The aeroelastic response calculations were performed for 2,300 time-steps corresponding to 4.6 revolutions of the fan. The aerodynamic behavior of the damaged fan is presented first to illustrate the effect of blade motion. Subsequently, the aeroelastic response of the blades is presented and compared to the forced response calculations.

\section{Unsteady Aerodynamic Results}

The normalized total pressure ratio and normalized referred mass flow rate as a function of fan revolution are shown in Fig. 16(a), During the first 1.5 fan revolutions, the unsteady operating point displays behavior similar to that without blade motion in Fig. 12(a). Namely, the total pressure ratio and referred mass flow first increase slightly from their initial value and then begin to decrease. In contrast to the case without blade motion, after 1.5 revolutions the total pressure ratio and referred mass flow rate continue to decrease. At 4.6 revolutions, the normalized referred mass flow rate has decreased from the steady-state value of $8.2 \%$ to $19.6 \%$. The unsteady total pressure ratio and referred mass flow rate are plotted on the fan map in Fig. 16(b) and exhibit behavior indicative of stall in which the unsteady operating point decreases below and to the left of the stall point. The progression of the operating point away from the operating line may result from the bypass duct static pressure boundary condition being too large, since it was set based on the steady-state aerodynamic calculations without blade motion. Further calculations will be performed to determine if the damaged fan will recover from the stall and to assess the affect of bypass duct static pressure on the unsteady aerodynamic behavior for the case with blade motion.

Unsteady Mach number contours at the mid-chord are shown in Fig. 17 for 8 equally spaced time-steps spanning the first 4.4 revolutions of the aeroelastic calculation. The corresponding total pressure ratio and referred mass flow rate at these time-steps are indicated by the fine vertical lines in Fig. 16(a). Similar to the case without blade motion, limited flow unsteadiness is evident in the vicinity of the damaged blades, where as the stalled flow at the blade tips of the undamaged sector is the dominant unsteady flow behavior. From Fig. 17(a) to 17(e) the aerodynamic environment from the aeroelastic case behaves similarly to the case 


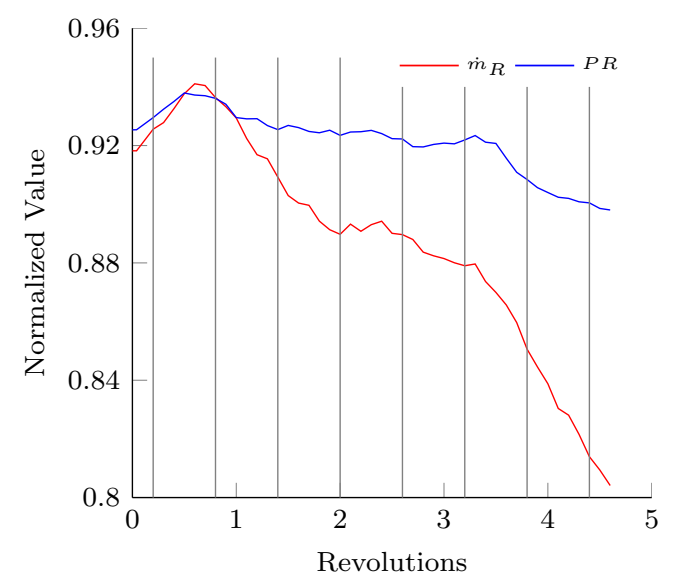

(a) Referred mass flow rate and total pressure ratio time history.

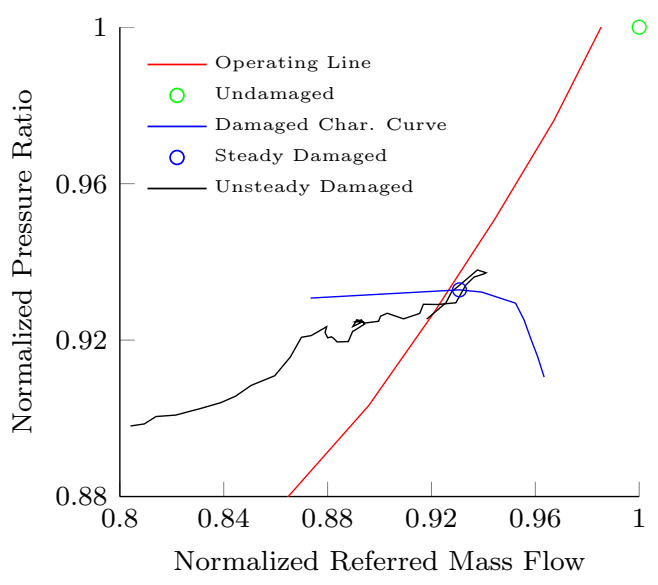

(b) Fan map with characteristic curve and steady and unsteady operating points.

Figure 16: Unsteady total pressure ratio and referred mass flow rate from aeroelastic calculations.

without blade motion. Specifically, in Fig. 17(b) the stall cell emanating from the damaged sector covers roughly a third of the fan wheel, from blade 20 to blade 5 , and the mass flow rate is near its maximum. From Fig. 17(c) to $17(\mathrm{e})$, the stall cell detaches from the damaged sector, progresses opposite the direction of rotation, and dissipates at in Fig. 17(f). At this point, the flow fails to recover and a stalled region forms in Fig. 17(h) that encompasses $5 / 6$ of the blade tips accompanied with a further decrease in referred mass flow rate. Overall, the influence of the structural response of the aerodynamic behavior of the damaged fan is evident, with the blade motion causing stalled flow for a majority of the fan.

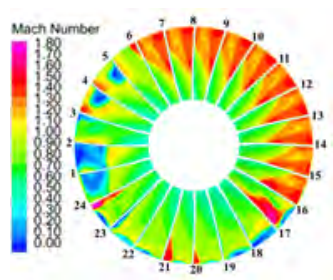

(a) 0.2 revolutions.

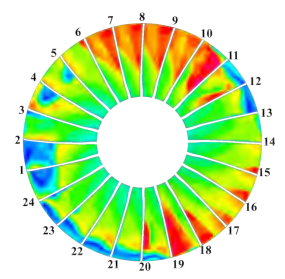

(e) 2.6 revolutions.

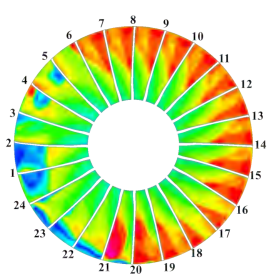

(b) 0.8 revolutions.

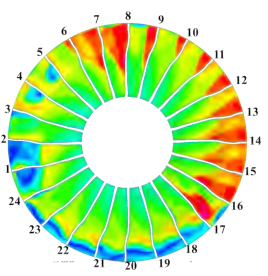

(f) 3.2 revolutions.

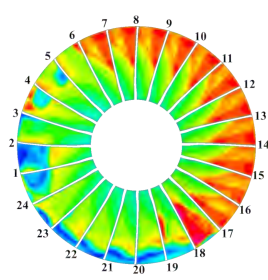

(c) 1.4 revolutions.

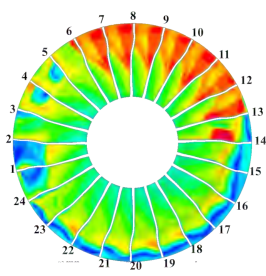

(g) 3.8 revolutions.

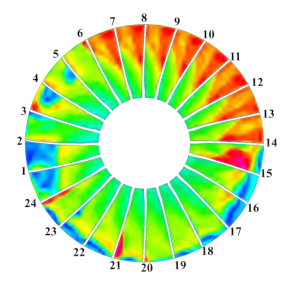

(d) 2.0 revolutions.

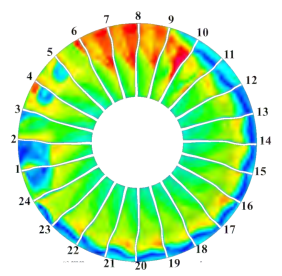

(h) 4.4 revolutions.

Figure 17: Unsteady Mach number contours of the damaged blade at mid-chord from aeroelastic calculations(direction of rotation: clockwise).

\section{Aeroelastic Blade Response}

The circumferential displacement, $u_{\theta} R$, at the leading edge of the blade tips is presented in Figs. 18 for the duration of the aeroelastic response calculations. The displacement is calculated relative to the steady-state configuration in which rotational velocity and steady-state CFD loads have been introduced, and blades 
with similar responses are grouped together. Overall, the aeroelastic response of the fan blades is similar to the forced response results, particularly for the undamaged blades. The largest tip displacements occur for blades 15-21 and grow in time, as shown in Fig. 18(a). In Fig. 18(b), blades 7-14 exhibit a limited structural response for the first 2 revolutions until the stall cell releases from the damaged sector and progresses through this region of the fan yielding a sudden increase in tip displacement. Between 3.8 and 4.4 fan revolutions, a large region of stalled flow progresses through to region resulting in a second increase in tip displacement. In Fig. 18(d), blades 22-24 exhibit smaller tip displacements that remain bounded with time. When compared to the forced response results in Fig. 14(d), the tip displacements for blades 22-24 are smaller in magnitude and contain a higher frequency content that indicates a higher structural mode is participating in the response of these blades. Finally, the tip displacements of blades 1-6 in Fig. 18(a) are the smallest; however, the aeroelastic response of these blades contains a higher frequency component than those from the forced response calculation shown in Fig. 14(a).

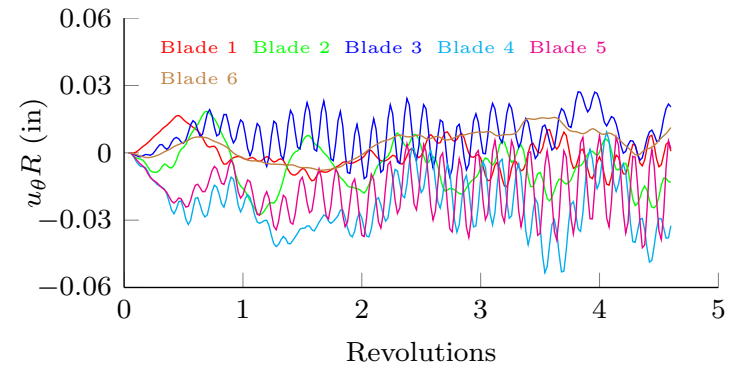

(a) Relative tip displacements for blades 1-6.

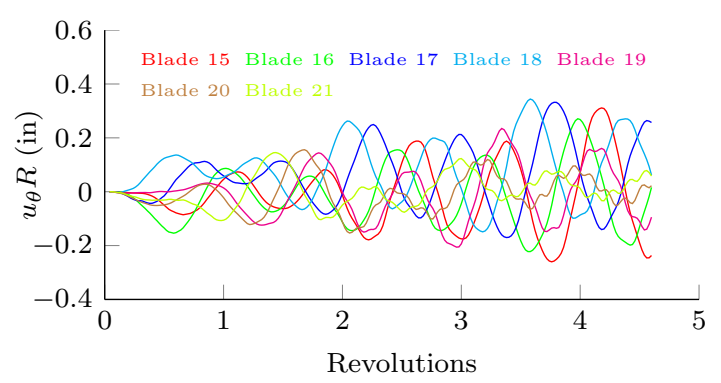

(c) Relative tip displacements for blades 15-21.

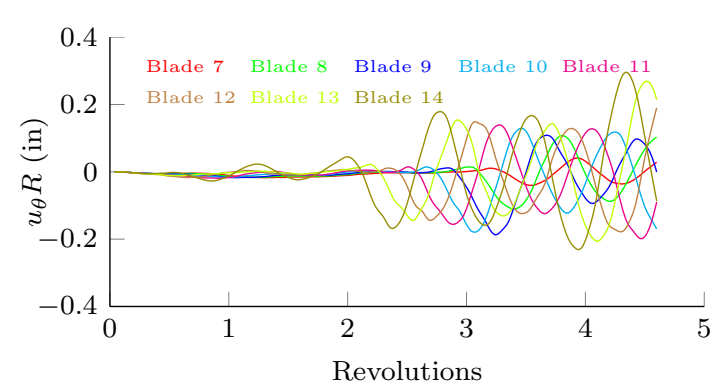

(b) Relative tip displacements for blades 7-14.

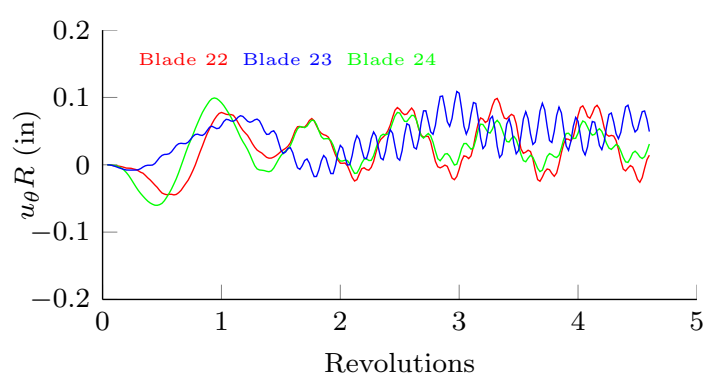

(d) Relative tip displacements for blades 22-24.

Figure 18: Aeroelastic response tip displacements, relative to the steady-state configuration.

The circumferential displacement together with the contributions from the first 5 natural modes are shown in Figs. 19 for the same representative blades in Fig. 15. Similar to the forced response results, the tip displacement of blade 12, shown in Fig. 19(b) is dominated by the first bending mode and decays slightly in time following the jump in structural response at $\sim 2$ revolutions. Furthermore, the tip displacement of blade 16 in Fig. 19(c) grows in time with the first bending mode dominating the response. The tip displacement of blade 5, shown in Fig. 19(a), is initially dominated by the first bending mode. However, the second torsion mode grows rapidly in time and dominates the blade response after $\sim 2$ fan revolutions. The rapid growth of the second torsion mode is unique to the aeroelastic response of blade 5 and may indicate an aeroelastic instability. The response of blade 24 in Fig. 19(d) is also initially dominated by the first bending mode; however, after $\sim 1$ revolution, the second torsion mode becomes increasingly dominant and the amplitude exhibits a "beating" behavior that is more significant than that of the forced response results.

Overall, the first bending mode is dominant in the forced response and aeroelastic response of all blades, with the amplitude of this mode growing for blades 7-18 due to the unsteady stall cell downstream of the damaged sector. The tip displacements from the aeroelastic response calculations also contain contributions from the first and second torsion mode that may be significant (as in the case of blades 1, 3-5, and 24) and may grow in time or exhibit "beating". Comparison of the two columns in Table 3 reveals some fundamental differences between the forced response and aeroelastic response of the damaged fan. For the forced response case, the primary response of the blade is in the fundamental bending mode, with occasional minor torsional 


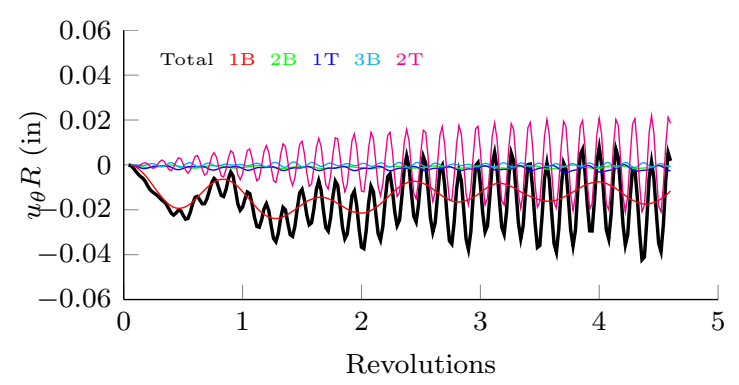

(a) Relative tip displacements for blade 5 .

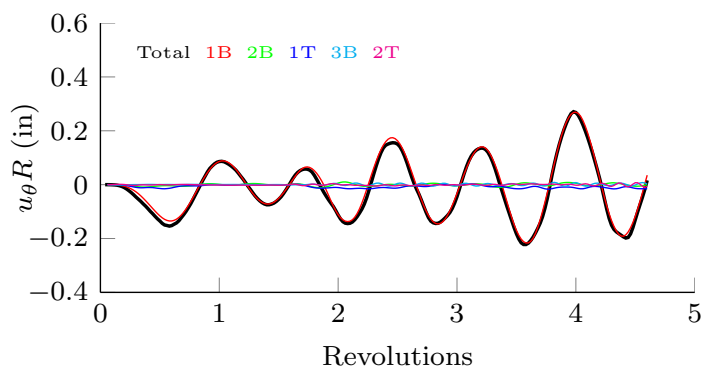

(c) Relative tip displacements for blade 16 .

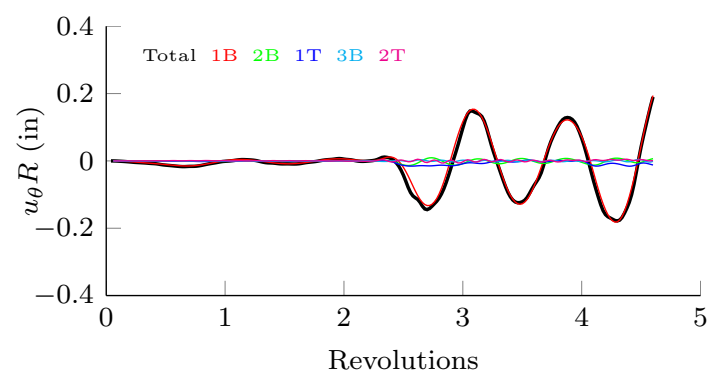

(b) Relative tip displacements for blade 12 .

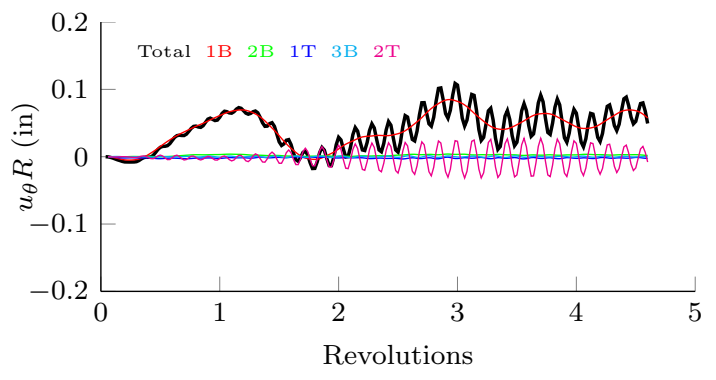

(d) Relative tip displacements for blade 24 .

Figure 19: Aeroelastic response tip displacements and the modal contributions of the first 5 natural modes.

participation primarily in the second torsion mode. The participation of the torsion degree of freedom is much more evident in the aeroelastic response column. The presence of both first and second torsional mode is evident in the modal participation, which is not surprising when recognizing that aeroelastic stability is intimately related to a coupled bending-torsion mechanism.

\section{Aerodynamic Work Comparison}

The aeroelastic stability of the fan blades is difficult to assess due to the inherent unsteadiness in the aerodynamic environment caused by the bird damage. Common approaches to determine the aeroelastic stability of a structure often rely on calculating the aerodynamic damping associated with the growth or decay of the blade response. However, the unsteady aerodynamic loads associated with a bird damaged fan may excite the blades causing a growth in blade response that is independent of aeroelastic effects.

To provide insight into the cause of the growing blade response in the aeroelastic response calculations, the work performed by the aerodynamic forces on the structure is calculated and compared to the forced response calculations. The aeroelastic stability is inferred based on the sign of the aerodynamic work. Negative aerodynamic work implies an energy transfer from the blade to the flow and indicates a stable response. Positive aerodynamic work implies an energy transfer from the flow to the blade and indicates an unstable response. The aerodynamic work of the entire blade is calculated for the forced response and aeroelastic response using Eq. (17) and Eq. [18, respectively.

$$
\begin{gathered}
W_{F R}(t)=\int_{0}^{t} \mathbf{F}_{\text {aero }}(\hat{t}) \cdot \dot{\mathbf{U}}(\hat{t}) d \hat{t} \\
W_{A R}(t)=\int_{0}^{t} \mathbf{F}_{\text {aero }}(\hat{t}, \mathbf{U}, \dot{\mathbf{U}}, \ddot{\mathbf{U}}) \cdot \dot{\mathbf{U}}(\hat{t}) d \hat{t}
\end{gathered}
$$

The aerodynamic work as a function of fan revolutions is presented in Fig. 20 for blades 5, 12, 16, and 24. The aerodynamic work from the forced response calculations is compared to aerodynamic work from the aeroelastic response calculations to identify possible aeroelastic instabilities. In Fig. 20(a), the aerodynamic work on blade 5 from the aeroelastic response calculations is positive and grows at a rate greater than that of the forced response calculations indicating the potential for aeroelastic instability of the blade. This behavior supports the claim that the rapid growth of the second torsion mode in Fig. 19(a) is due to an 
aeroelastic mechanism. The aerodynamic work from the forced response for blade 5 is also positive and grows slowly in time, demonstrating that the unsteady aerodynamic loading contributes energy to the blade. The aerodynamic work from the forced response and aeroelastic response calculations for blades 12 and 16 are similar, as shown in Figs. 20(b) and 20(c) For these blades, the aerodynamic work from both cases grows slowly with time at approximately the same rate, suggesting that the growth in blade response is due to the unsteady aerodynamic loads caused by the stall cell rather than an aeroelastic instability. The aerodynamic work for blade 24 from the aeroelastic response calculations is predominantly negative compared to the forced response case, as shown in Fig. 20(d), This suggests that the aeroelastic effects produce positive aerodynamic damping. Overall, the aerodynamic work from the aeroelastic response calculations is similar to that from the forced response calculations except for blade 5. The growth in blade response for all blades appears to be dominated by the unsteady aerodynamics caused by the damaged blades, with the exception being blade 5 that exhibits a possible aeroelastic instability of the second torsion mode.

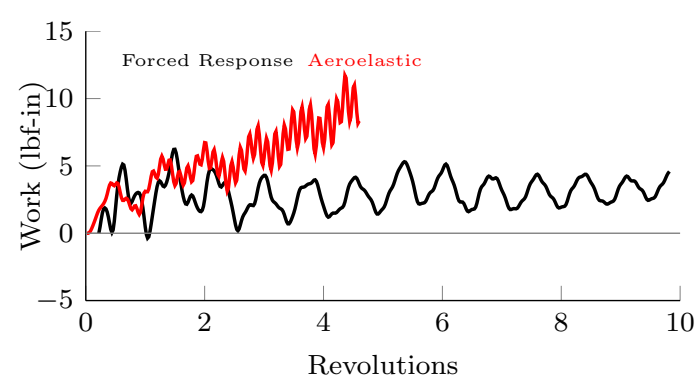

(a) Aerodynamic work for blade 5 .

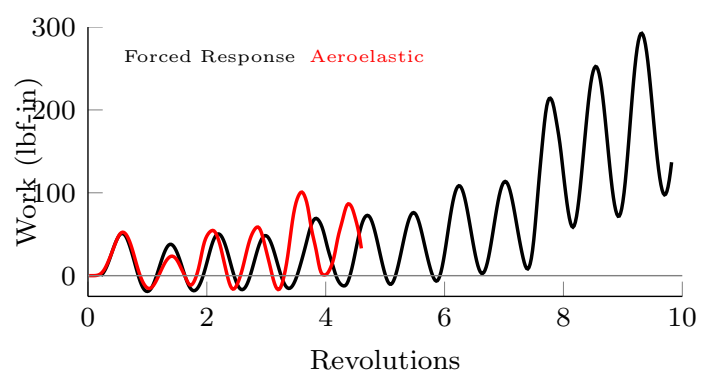

(c) Aerodynamic work for blade 16 .

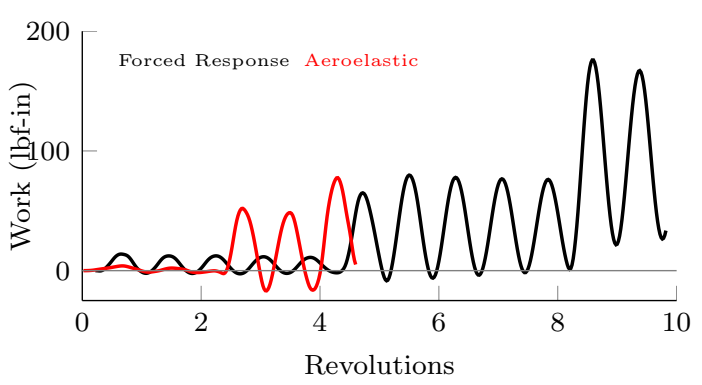

(b) Aerodynamic work for blade 12 .

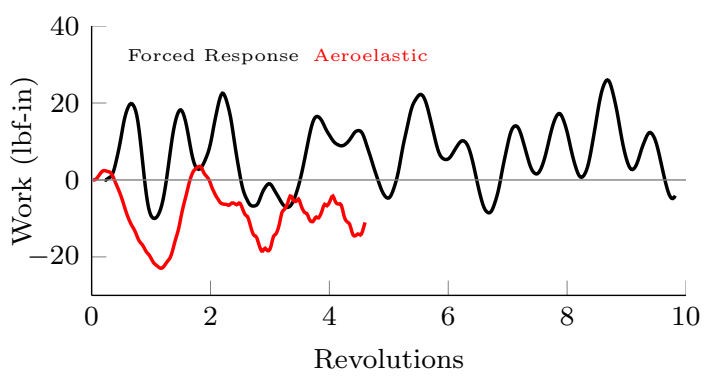

(d) Aerodynamic work for blade 24 .

Figure 20: Comparison of aerodynamic work from the forced response and aeroelastic response calculations.

\section{Concluding Remarks}

The forced response and aeroelastic response of a bird-damaged fan is examined using a coupled computational fluid dynamics (CFD) and computational structural dynamics (CSD) framework. The aerodynamic model is based on the ANSYS CFX code, which is used to perform the steady-state and unsteady CFD calculations for a bird-damaged fan. Subsequently, ANSYS Mechanical APDL is coupled with ANSYS CFX using the ANSYS Multifield solver to perform a one-way forced response and fully-coupled aeroelastic response calculations of a bird-damaged fan. The damaged configuration resembles a realistic bird strike damage that covers a sector of 5 fan blades in which the damage includes substantial leading-edge deformation and global bending and untwist of the blades.

The steady-state CFD calculations of the damaged fan show a flow loss of $8.2 \%$ and the characteristic curve indicates that the damaged fan is operating near stall where unsteadiness in the flow is significant. Furthermore, the aerodynamic behavior of the damaged fan exhibits unsteadiness, particularly in the region downstream of the damaged sector where a stall cell emanating from the damaged sector progresses at the blade tips.

The forced response calculations show that the undamaged blades downstream of the damaged sector 
exhibit the greatest blade tip displacement and the amplitude of the displacement grows in time. The blade tip displacements for all blades are dominated by the first bending mode, and the tip displacement for the damaged blades also include small contributions from the first and second torsion modes.

The structural response resulting from the fully-coupled aeroelastic calculations is similar to that from the forced response calculations. The largest tip displacement occurs for the undamaged blades downstream of the damaged sector and the amplitudes grow in time. The structural response of all blades is dominated by the first bending mode; however, contributions from the second torsion mode are significant for the damaged blades. Specifically, the amplitude of the second torsion mode grows rapidly in time for the upstream damaged blade.

The aerodynamic work exerted by the aerodynamic forces is calculated and compared for both the forced response and aeroelastic calculations. In general, the growth in blade response appears to be due to the unsteady aerodynamic loads caused by the damaged fan blades rather than by an aeroelastic mechanism. However, the aerodynamic work for the upstream damaged blade suggests that the rapid growth of second torsion mode may be due to an aeroelastic instability.

\section{References}

${ }^{1}$ Teichmann, H. C. and Tadros, R. N., "Analytical and Experimental Simulation of Fan Blade Behavior and Damage Under Bird Impact," Journal of Engineering for Gas Turbines and Power, Vol. 113, No. 4, October 1991, pp. 582-594.

${ }^{2}$ Isomura, K. and Giles, M. B., "A Numerical Study of Flutter in Transonic Fan," Journal of Turbomachinery, Vol. 120, No. 3, July 1998, pp. 500-507.

${ }^{3}$ Horsley, J., "The 'Rolls-Royce' Way of Validating Fan Integrity," AIAA Paper No. 93-2602, AIAA/SAE/ASME/ASEE 29th Joint Propulsion Conference and Exhibit, Monterey, CA, June 1993, pp. 1-22. 594 .

${ }^{4}$ Bendiksen, O. O., "Aeroelastic Problems in Turbomachines," Transactions of the ASME, Vol. 113, October 1991, pp. 582-

${ }^{5}$ Bendkisen, O. O., Kielb, R. E., and Hall, K. C., "Turbomachinery Aeroelasticity," Encyclopedia of Aerospace Engineering, John Wiley \& Sons, 2010.

${ }^{6}$ Eschenfelder, P., "Jet Engine Certification Standards," Proceedings of the International Bird Strike Committee, Amsterdam, April 2000, pp. 535-540.

${ }^{7}$ Howard, W. D., "Turbofan Engine Bird Ingestion Testing," AIAA Paper No. 1991-2380, Proceedings of the 27th Joint Propulsion Conference, Sacramento, CA, June 1991.

${ }^{8}$ Kim, M., Vahdati, M., and Imregun, M., "Aeroelastic Stability Analysis of a Bird-Damaged Aeroengine Assembly," Journal of Aerospace Sciences and Technologies, Vol. 5, No. 7, 2001, pp. 469-482.

${ }^{9}$ Imregun, M. and Vahdati, M., "Aeroelastic Analysis of a Bird-Damaged Fan Assembly Using a Large Numerical Model," The Aeronautical Journal, Vol. 103, No. 1030, December 1999, pp. 569-578.

${ }^{10}$ Goyal, V. K., Huertas, C. A., Borrero, J. R., and Leutwiler, T. R., "Robust Bird-Strike Modeling Based on ALE Formulation Using LS-DYNA," AIAA Paper No. 2006-1759, Proceedings of the 47th AIAA/ASME/ASCE/AHS/ASC Structures, Structural Dynamics, and Materials Conference, Newport, RI, May 2006.

${ }^{11}$ Hirschbein, M. S., "Bird Impact Analysis Package for Tubine Engine Fan Blades," AIAA Paper No. 1982-696, Proceedings of the 23rd AIAA/ASME/ASCE/AHS/ASC Structures, Structural Dynamics, and Materials Conference, New Orleans, LA, May 1982.

${ }^{12}$ Mao, R., Meguid, S. A., and Ng, T. Y., "Finite Element Modeling of a Bird Striking an Engine Fan Blade," Journal of Aircraft, Vol. 44, No. 2, 2007, pp. 583-596.

${ }^{13}$ Mao, R., Meguid, S. A., and Ng, T. Y., "Transient Three Dimensional Finite Element Analysis of a Bird Striking a Fan Blade," International Journal of Mechanics and Materials in Design, Vol. 4, No. 1, 2008, pp. 79-96.

${ }^{14}$ Meguid, S. A., Mao, R., and Ng, T. Y., "FE Analysis of Geometry Effects of an Artificial Bird Striking an Aeroengine Fan Blade," International Journal of Impact Engineering, Vol. 35, No. 6, 2008, pp. 487-498.

${ }^{15}$ Nizampatnam, L. S. and Horn, W. J., "Investigation of Equation of State Models for Predicting Bird Impact Loads," AIAA Paper No. 2008-682, Proceedings of the 46th AIAA Aerospace Sciences Meeting and Exhibit, Reno, NV, January 2008.

${ }^{16}$ Shimamura, K., Shibue, T., and Grosch, D. J., "Numerical Simulation of Bird Strike Damage on Jet Engine Fan Blade," Proceedings of the ASME/JSME Pressure Vessels and Piping Conference, San Diego, CA, July 2004.

${ }^{17}$ Aotsuka, M. and Tsuchiya, N., "Numerical Simulation of Transonic Fan Flutter with 3-D N-S CFD Code," Proceedings of the ASME Turbo Expo 2008: Power for Land, Sea, and Air, Berlin, Germany, June 2008.

${ }^{18}$ Marshall, J. G. and Imregun, M., "A Review of Aeroelasticity Methods with Emphasis on Turbomachinery Applications," Journal of Fluids and Structures, Vol. 10, No. 3, 1996, pp. 237-267.

${ }^{19}$ Muir, E. R. and Friedmann, P. P., "Unsteady Aerodynamic Analysis of a Bird-Damaged Turbofan," AIAA Paper No. 2013-1773, Proceedings of the 54th AIAA/ASME/ASCE/AHS/ASC Structures, Structural Dynamics, and Materials Conference, Boston, MA, April 2013.

${ }^{20}$ Muir, E. R. and Friedmann, P. P., "Unsteady Aerodynamic Loading on Bird-Damaged Fan Blades and Its Effect on Forced Response," Proceedings of the 2013 International Forum on Aeroelasticity and Structural Dynamics, Bristol, UK, June 2013.

${ }^{21}$ Morris, A., Allen, C., and Rendall, T., "CFD-based Optimization of Aerofoils Using Radial Basis Functions for Domain 
Element Parameterization and Mesh Deformation," International Journal for Numerical Methods in Fluids, Vol. 58, No. 8, 2008, pp. 827-860.

${ }^{22}$ van Zuijlen, A., de Boer, A., and Bijl, H., "Higher-order Time Integration Through Smooth Mesh Deformation for 3D Fluid-Structure Interaction Simulations," Journal of Computational Physics, Vol. 224, No. 1, 2007, pp. 414-430.

${ }^{23}$ Jakobsson, S. and Amoignon, O., "Mesh Deformation Using Radial Basis Functions for Gradient Based Aerodynamic Shape Optimization," Computers and Fluids, Vol. 36, No. 6, 2007, pp. 1119-1136.

${ }^{24}$ Buhmann, M. D., Radial Basis Functions: Theory and Implementations, Cambridge University Press, Cambridge, 2003.

${ }^{25}$ de Boer, A., van der Schoot, M., and Bijl, H., "Mesh deformation based on radial basis function interpolation," Computers E Structures, Vol. 85, No. 11, 2007, pp. 784-795.

${ }^{26}$ Lamorte, N. and Friedmann, P. P., "Hypersonic Aeroelastic Stability Boundary Computations using Radial Basis Functions for Mesh Deformation," AIAA Paper No. 2012-5943, Proceedings of the 18th AIAA/3AF International Space Planes and Hypersonic Systems and Technologies Conference, Tours, France, September 2012.

${ }^{27}$ Mechanical APDL Theory Reference Guide - Version 14.5, ANSYS, Inc., 2012.

${ }^{28}$ Hilber, H. M., Hughes, T. J. R., and Taylor, R. L., "Improved Numerical Dissipation for Time Integration Algorithm in Structural Dynamics," Earthquake Engineering and Structural Dynamics, Vol. 5, No. 3, July-September 1977, pp. $283-292$.

${ }^{29}$ Mechanical APDL Coupled-Field Analysis Guide - Version 14.5, ANSYS, Inc., 2012. 